\author{
University of Cologne \\ Faculty of Human Science \\ Department of Psychology
}

\title{
The Appraisal of Reactions to Success: \\ The Benefits and Costs of Humility
}

\author{
Johanna Werz \\ Master thesis
}

25.05.2017

Supervisor: Dr. Jan Crusius

Social Cognition Center Cologne: Social Psychology I

Johanna Werz

Student number: 6071473

Luxemburger Str. 323

50939 Köln

johanna.werz@hotmail.de

This study was supported by the C-SEB student grant 


\begin{abstract}
Although praised in popular media and desired as a reaction to success, little is known about the perception of humility. In social interactions, competence and liking are two crucial appraisal dimensions. The present research determines the effect of a humble vs. a proud expression on these two dimensions. Participants $(N=199)$ took part in a word competition and then read their alleged opponents' reaction to victory. The reactions were proud, neutral, or humble. In line with its prosocial nature, humility elicited more warmth/liking than a neutral statement, whereas pride led to less warmth/liking. Pride, conveying high status and success, was expected to lead to higher appraisals of competence than humble or neutral demeanor. However, the three expressions neither affected competence perceptions differently nor influenced the amount of money participants bet on their opponent winning again as a behavioral measure of competence. Exploratory ANCOVAs and correlations hint towards the hypothesis of pride conveying slightly more competence than humility. Relations and effects of authentic pride and hubristic pride as well as appreciative humility and selfabasing humility are reviewed. Explanations like the influence of prior success and the interplay of warmth and competence are discussed and applied to individual advice and social implications.
\end{abstract}

Keywords. Humility, pride, perception, liking, warmth, competence 
Table of content

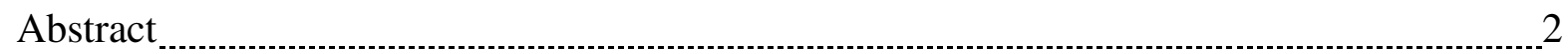

Table of content

Introduction

Pride

Humility

The current research

Method

Participants

Procedure and material

Pretest

Results 26

Manipulation check

Dependent variables

Exploration 33

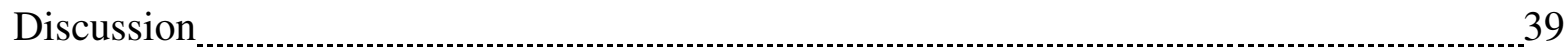

Limitations

Conclusion 47

References

Appendix

Declaration of academic honesty 62 
The Appraisal of Reactions to Success: The Benefits and Costs of Humility

Bescheidenheit ist eine Zier, doch weiter kommt man ohne ihr.

Humility might be a grace, forget it if you want to win the race.

(Old German proverb)

Winning the race, being successful, living up to our potential is a motivation that drives most of us (Anderson, Hildreth, \& Howland, 2015). As old as this drive is the search for the appropriate means that make us more highly achieving people. According to the old German proverb, humility is not one of these. Voices from modern business and media, however, disagree. Lazlo Bock, Google's Senior Vice President of People Operations, states that he looks for humility when recruiting new employees (Anders, 2014). The Harvard Business Review declares "[t]he best leaders are humble leaders" (Prime \& Salib, 2014) and the Foster School of Business states that "[h]umility is a key to [...] effective leadership" (2012). On the contrary, leadership is still associated with agentic behavior, such as assertiveness and competitiveness (Koenig, Eagly, Mitchell, \& Ristikari, 2011). Studies show that agentic reactions like anger or pride make observers infer higher competence and status from the sender than if he or she was showing less agentic emotions like sadness or appreciation (Tiedens, Ellsworth, \& Mesquita, 2000). Specifically, pride is associated with success and communicates high status and achievement to observers (Tracy \& Robins, 2007a). This function of pride contradicts the popular voices that claim you have to be humble to be successful. Thus, do you have to forget humility and act proudly or is it better to foster your humble manners if you want to "win the race"? This study will address this question and attempt to provide answers.

The implications of how humility versus pride affect interpersonal perceptions range from an individual to a societal level. In one study (Wosinska, Dabul, Whetstone-Dion, \& 
Cialdini, 1996), for example, managers preferred a proud self-presentation over a humble one from their employees. On the contrary, colleagues expected their coworkers to react humbly to success. Women in the workplace face a similar dilemma: The average manager is still seen as agentic, dominant, and aggressive — all traits closely related to masculinity (Eagly \& Carli, 2007). Women, in contrast, are expected to present themselves more humbly than their male counterparts (Wosinska et al., 1996). Violating this norm is punished with social disregard (Eagly \& Carli, 2007; Heilmann, 2001), which is why women react more humbly to success than men (Daubman, Heatherington, \& Ahn, 1992; Singh, Kumra, \& Vinnicombe, 2002). That is, proudly behaving "women pay the price for counter-stereotypical behavior, even though it may be required for a successful career" (Rudman, 1998, p. 642). These structural differences between the perception of women and men, but also the quandary to please both the boss and one's coworkers, raise the question of the appraisal of humility in comparison to pride. Does a humble reaction in itself put the sender at a relative disadvantage compared to a proudly behaving person?

Despite the problematic aspects of humility on the labor market, studies show the positive effect humility has on social life. Humility correlates with a higher social relationship quality, with a faster repair of social bonds, and people like and prefer to be friends with humble individuals rather than proud ones (Davis et al., 2013; Kalokerinos, Greenaway, Pedder, \& Margetts, 2014; Peters, Rowatt, \& Johnson, 2011). Pride, on the contrary, shows associations to decreased liking and envy (Lange \& Crusius, 2015). The question arises, how do observers appraise a humble in comparison to a proud reaction to success?

The answer to this question concerns all of us, not only when the best of us give the acceptance speech for the Nobel Prize, but also when we face salary negotiations, date the love of our life, or talk to colleagues about our successful project. Our demeanor in these situations always prompts observers' appraisals. According to appraisal theory, evaluations of 
other people's behavior are more central to an observer's emotions, cognitions, and behavior than their actual behavior (Smith \& Lazarus, 1990). Thus, the statement that emotions "are the [...] cause of social behaviors" (Cuddy, Fiske, \& Glick, 2008, p. 71) does not only mean that an individual's emotions trigger this individual's behavior. Emotions are also "powerful sources of social and moral information" (Horberg, Kraus, \& Keltner, 2013, p. 24), meaning emotional expressions themselves trigger appraisals, emotions and finally behavior in observers. It is not only important to know what happens when someone feels pride or humility, how it is enacted or how a person behaves when experiencing it. Even more, knowledge about how observers perceive humility is crucial for explaining consequences for the humble person and predicting further interaction. Therefore, this study investigates the appraisal of humility and pride. The results are relevant for those who want to win the race and those who find themselves in the quandary of being both an employee and a colleague. They could add to discussions regarding topics, such as the structural disadvantage of humbly behaving women, and might even help prospective Nobel Prize winners to prepare for their thank-you speech.

Two very prominent appraisal dimensions that have already been addressed indirectly are liking and competence. They are, according to the stereotype content model (SCM; Fiske, Cuddy, Glick, \& Xu, 2002), the two most central dimensions when appraising others. According to this model, people evaluate others first on the dimension of warmth, which can be used interchangeably to liking. That is, they evaluate the other person's goals, from low warmth (competing goals, high competition) to high warmth (shared goals, low competition). Second, they estimate the competence, which describes his or her ability to pursue these goals (high to low). Warmth/liking and competence not only play a major role in appraisal theories like the SCM, they also constitute two dimensions that have wide-ranging influence on how people perceive, approach, and treat each other. Therefore, this paper will investigate the 
following question: What are the benefits and costs of reacting humbly versus proudly to success concerning liking and competence?

As demonstrated, popular and academic voices offer diverging answers to this question. Whereas pride seems to be linked to the expression of a higher status at the expense of liking (Kalokerinos et al., 2014; Tiedens et al., 2000), humility seems to promote a prosocial perception by others (Davis et al., 2013). But despite being discussed in popular media, the relation of humility to competence perceptions has not yet been clarified, nor have researchers compared the effects of pride vs. humility on liking and competence appraisals.

\section{Pride}

Pride is the positive emotion triggered by individual success (Tracy \& Robins, 2007a), when we "receive or take credit [...] for the positive event and experience ego-enhancement" (Lazarus, 1991, p. 271). Furthermore, it is associated with both self-focus and self-promotion (Tracy \& Robins, 2007a). As an emotion, pride "confirms and enhances personal worth" (Lazarus, 1991, p. 271) by increasing one's self-esteem. However, it also operates interpersonally for self-promotional ends by presenting "one's worthy self or action to others" (Mascolo \& Fischer, 1995, p. 66). In this vein, proud reactions to success facilitate people's access to resources (Shiota, Keltner, \& John, 2006) and convey high status and competence in comparison to less agentic reactions like appreciation (Tiedens et al., 2000). In a vignette study, participants expected high-status members to show anger and pride more often than sadness and appreciation. Also, participants expected people that were described as showing anger or pride to belong to the high-status group rather than to a low-status group - to be a manager rather than an employee (Tiedens et al., 2000). Pride led to ascriptions of a higher status. Higher status, in turn, causes higher ascriptions of competence, as Caprariello, Cuddy, 
and Fiske (2009) demonstrated in a validation of the stereotype content model. Extrapolating from pride to competence seems empirically reasonable: Proud participants performed better and showed more problem-focus than angry or shameful participants (Herrald \& Tomaka, 2002). In the study, people were randomly assigned to an emotion condition (pride vs. anger vs. shame) in which they received fake feedback according to condition. When participants' problem-solving strategies and competence were assessed during and after this induction, proud participants performed best. According to this study, relating pride to competence in an observed person is an adequate, reasonable association.

In addition to being competent, proudly reacting people are also perceived as being more competitive, having a higher self-interest and holding a world-view that benefits the self - meritocratic instead of egalitarian (Horberg et al., 2013). In videos of mock job interviews, targets were describing their greatest strengths. Participants then rated the short videos and the targets, and estimated how the interviewees would distribute money between themselves and somebody else. In line with Horberg et al.'s predictions, higher ratings of pride (vs. joy) predicted higher ascribed selfishness of the target, which explained to a great extent the expected allocation of resources according to merits (vs. equality). This finding suggests that a proud reaction alters the observers' perception of the proud person, which corresponds to appraisal theory. In the case of pride, the ascriptions change towards more selfish- and competitiveness.

The perception of a high self-focus already hints to the fact that pride is not perceived as a very prosocial or socially desirable emotion. Besides pride being ranked among the highest of the deadly sins (Flüeler, 2009), studies show that people prefer to be friends with humble individuals than proud ones (Kalokerinos et al., 2014) and that pride can lead to decreased liking and more envy (Lange \& Crusius, 2015). But to see the whole picture, an important differentiation should be considered when talking about pride. Lange and Crusius 
(2015) make use of it in their research when referring to a two-sided definition of pride. This differentiation answers the question why sometimes pride is a socially accepted, self-esteem increasing, status-conveying emotion, whereas, in other instances, it is seen as a deadly sin and related to arrogance and selfishness. These two faces of pride are mirrored in two distinct forms, namely authentic and hubristic pride (Tracy \& Robins, 2007b). Hubristic pride is the grandiose type, associated with arrogance and selfishness, and results from attributing success to stable characteristics of the self. Authentic pride, by contrast, is the more prosocial type, assigned to a confident, successful, and productive person, whose pride results from specific accomplishments (Tracy \& Robins, 2007b). Both types of pride show relations to higher narcissism - and to self-esteem. However, the association of self-esteem and authentic pride is positive, whereas it correlates negatively with hubristic pride. Thus, it is reasonable that hubristic pride is the type that elicits more negative emotions in observers, like schadenfreude, antagonism, and less liking (Lange \& Crusius, 2015; Tracy \& Robins, 2007b). The main message is clear: Hubristic pride elicits more negative, unappealing appraisals about the person, whereas authentic pride is the more desirable of the two facets. In sum, pride is a status conveying emotion shown after success. It leads to competence perceptions but might reduce liking.

\section{Humility}

A different reaction to success is humility. Its concept is still debated within the psychological community. Some theorists contrast humility to pride, because just as pride involves appreciating one's merits, humility “involves appreciating one's limitations” (Lazarus, 1991, p. 272). Others see guilt and shame as opposites of pride (Mascolo \& Fischer, 1995) and narcissism as opposite of humility (Tangney, 2000). Despite focusing on these conceptualizations, this paper will regard humility as one alternative reaction to success 
besides pride. Among its multiple definitions, honesty-humility emerged as one factor in the HEXACO, a personality structure similar to the Big Five but consisting of six factors (Ashton et al., 2004; Hilbig, Zettler, \& Heydasch, 2012). Although many researchers have investigated humility as a disposition and trait (e.g. Exline \& Geyer, 2004; Peters et al., 2011; Tangney, 2000), Chancellor and Lyubomirsky (2013) claim it to be both trait and state:

"Of course, trait humility exists, and others identify particular individuals as humble precisely because they exhibit cross-situational consistency in their behavior. At the same time, people can also recall specific moments when they felt particularly humble (i.e., situational humility).”(p. 821)

In their subsequent explication, they make one important point: Focusing on humility as a state can complement the understanding of humility as a trait. One reason is that it is easier to investigate specific events that do not comprise each aspect of humility, but which still help to understand its components, antecedents, and outcomes. This study follows this reasoning. It is evident that one single statement, as presented in this study, cannot convey humility in its full breadth. But firstly, in real life, we frequently base our evaluations on smallest slices of human behavior (Ambady \& Rosenthal, 1992; Horberg et al., 2013). Secondly, humility as a reaction to success offers the opportunity to investigate on the perception of humility in straightforward and daily interpersonal settings. As a first step in humility perception research, knowledge about its effect on liking and competence builds a base for further investigations about humility.

Despite the ongoing debate, some researchers agree on criteria of what constitutes humility. Although there is a general lack of studies on the perception of humility, the recent studies have worked with the following conceptualization: Humility is (a) other-focused rather than self-focused, (b) marked by a lack of superior self-evaluation and (c) contains an accurate view of the self, which is not too inflated or too low (e.g. Ashton et al., 2004; 
Chancellor \& Lyubomirsky, 2013; Davis et al., 2011; Exline \& Geyer, 2004; Hilbig et al., 2012; Kesebir, 2014; Lazarus, 1991). As this definition has proven successful is earlier research, it is sharp and clear, and interpersonally applicable, it served as the base of humility in this study, too. Therefore, the study's experimental condition representing humility (vs. pride) was developed according to this definition.

Distinguishing between modesty and humility is crucial when defining terms. Although some researchers have used the two nearly interchangeably (e.g. Gregg, Hart, Sedikides, \& Kumashiro, 2008; Schlenker \& Leary, 1982), according to Tangney (2000), modesty is both narrower and broader than humility. It is broader in the sense that it involves the ownership of objects (e.g. clothes) and actual behavior. But it is also narrower, as it misses factors like a "forgetting of the self" (p. 70) and the appreciation of other people's worth. Many researchers agree on the fact that humility and modesty are similar but contain different aspects. Thus, modesty has often been described as being the more superficial, behaviorrelated attribution. Modesty, in this sense, is a behavior complying with cultural standards. It can mean "moderate praise" (Davis et al., 2011, p. 225), but can also be an underestimation of one's performance, depending on what is socially desirable in that situation (Chancellor \& Lyubomirsky, 2013; Davis et al., 2016). Whereas very often modest behavior is in line with humble behavior, modesty can also be the very opposite. To meet the cultural requirements, modesty can mean to present oneself worse than one is, despite better knowledge and one's conviction. A humble person would behave in line with his or her convictions, as an accurate self-view and sincere behavior are core features of humility (Chancellor \& Lyubomirsky, 2013). For instance, when someone worked very hard, a humble person would react happily about the achievement. This would be an expression in line with his or her inner feelings, demonstrating an accurate view of the self and sincerity but without being a braggart or feeling superior. Modesty, however, would mean to downplay the achievement, to present oneself as less happy as one feels, to behave insincerely but with polite modesty. The goal of 
the present study is to investigate the whole concept, which concerns behavior based on conviction attributable to personality, rather than cultural norms and politeness. Therefore, the study is put in line with research on the more sincere and underlying concept of humility rather than the more specific and superficial modesty.

Besides the question what humility is, several researchers have been committed to the issue of whether humility is positive or negative, a vice or virtue. In the 1980s and 90s, many studies found humility to have negative effects. However, this may stem mainly from a different conceptualization and operationalization of humility at that time. Schlenker and Leary (1982), for example, compared humble, proud, and neutral behavior and assessed their respective evaluation by observers. Whereas neutral behavior led to the most liking, both proud and humble statements impaired the evaluation. Statements about having performed poorly, especially before the announcement of the results, led to the most negative evaluations. This was true both when later results were better than predicted and when they were predictably poor. In contrast, statements to having performed well were perceived better, independently of how well the actual task was performed. The researchers believed that participants "seemed to assume that only a more competent person would predict better performances" even leading to the fact, that "they gave such actors the benefit of the doubt by partially discounting [later] poor performances” (Schlenker \& Leary, 1982, p. 95). Also, Powers and Zuroff (1988) found that self-critics received a "mixed message of support and denigration: 'You're not as bad as you say you are, but you're no great shakes either."' (p. 1060). In sum, participants evaluated self-critics as being "poorly functioning individuals" (p. 1061). They evaluated them as worse students and employees than the self-enhancers, with whom, however, they wanted to avoid future interaction. The self-critics experienced less professional but higher social appreciation. It has to be noted that these studies considered humility/modesty to be rather negative and operationalized humble behavior as criticizing 
oneself and as presenting oneself in a self-deprecating manner. This contradicts the current definition used here, in which accurately understanding oneself is essential.

Nevertheless, being among the few to try to investigate the perception of something similar to humble behavior, these studies do contain a significant finding: They suggest that a proud self-presentation might be perceived as less likable but more competent than a humble self-presentation. As Schlenker and Leary noted: “[...] people present themselves modestly in situations where they believe the audience knows of their successes, while presenting themselves self-enhancingly when they believe the audience does not" (1982, p. 91). This effect can be translated to humility because, toward strangers, people present themselves more favorably, but when presenting themselves to friends they do so more humbly (Tice, Butler, Muraven, \& Stillwell, 1995). People thus use the functionality of pride and humility to their favor. When others know about an individual's successes, there is no need to demonstrate them with pride. Moreover, behaving humbly helps maintain a good relationship. On the contrary, humility might withhold a message of success that pride conveys - maybe at the expense of liking.

The contemporary definition suggests a more positive picture of humility than in the past. Respective studies analyzing participants' descriptions of humility (i.e., associations, situations, people) show that they perceive it as a strength, even more so for spiritual leaders (Exline \& Geyer, 2004). Gregg et al. (2008) also propose the positive perception of humility in the general population. Their stereotype analysis examined the general understanding of modesty. However, the concept of humility was strongly intermingled with the positive clusters of modesty and vice versa. In the paragraph "What humility is not", Tangney (2000) explains that it is neither low self-esteem, nor "an underestimation of one's abilities, accomplishments, or worth" (p. 74). However, Tangney mentions that there might be a darker side of humility, too. Weidman, Cheng, and Tracy (2016) attended to this darker side, which, 
according to them, empirical researchers have long neglected. Humility, etymologically stemming from the Latin word humilitās, meaning lowness and insignificance (Klein, 1971), shows its negative side in these roots, but also in lexicon entries and philosophical essays. In this context, humility is often associated with a "low opinion of our merits" (Richards, 1988, p. 253), or an "antisocial, withdrawal-oriented feeling" (Weidman et al., 2016, p. 5). In parallel with the two types of pride (Tracy \& Robins, 2007a), the same research group discovered two types of humility: appreciative and self-abasing humility (Weidman et al., 2016). They affirmed this structure with semantic cluster analyses and in reports generated and analyzed by experts. They even induced the two kinds of humility, which led to two distinct emotional episodes and action tendencies. As its name indicates, appreciative humility elicits feelings of appreciation for oneself and others, typically follows success, and shows links to a personality based on achievements and authentic pride. Self-abasing humility, in contrast, typically follows failure, involves a negative picture of the self that wants to hide from others, and shows links to a personality based on withdrawal and shame (Weidman et al., 2016). It is noteworthy that this is the first paper differentiating these two types of humility. That leaves several questions unanswered, e.g. in regard to the underlying attributions of the two types, how and whether they are perceived by observers, or if they exist in other languages at all (e.g. German ${ }^{1}$ ).

Humility is not only a construct with a positive mainstream and stereotypical connotation. Being a humble person is also connected with positive consequences. According

\footnotetext{
${ }^{1}$ In German, humility can be translated with "Bescheidenheit", as done here. An alternative translation is "Demut", a rather Christian and spiritually connoted construct. Nevertheless, academics have not yet addressed a psychological differentiation in German, let alone investigated any subtypes of either Bescheidenheit or Demut. I propose that neither the constructs of modesty nor humility are completely transferable into Demut or Bescheidenheit. For an everyday understanding of humility, as it is investigated in the present study, I chose the more common translation "Bescheidenheit" and expected this to be as accurate as possible.
} 
to recent research, humility fosters well-being, happiness, life satisfaction, and reduces anxiety (Kesebir, 2014; Krause, Pargament, Hill, \& Ironson, 2016). Humble people have better social bonds (Davis et al., 2013; Peters et al., 2011), and people prefer to be friends with humble individuals rather than with proudly acting people (Kalokerinos et al., 2014). This notion is well in line with recent studies showing that humble people are generous, helpful, and repair their social bonds more easily (Davis et al., 2013; Exline \& Hill, 2012; LaBouff, Rowatt, Johnson, Tsang, \& Willerton, 2012). By and large, research shows that humble people are more prosocial, an association also demonstrated by an experiment by Hilbig and his colleagues (2012). Having filled out a scale measuring personality factors, including trait humility, the participants played the public goods game. This game entails several people deciding for themselves whether to share or keep a certain amount of money. The collective of participants benefits most when everybody cooperates. Nevertheless, not cooperating — free riding — leaves the individual with more money as the free rider still profits from the money shared by others. This means, one earns most if everybody else cooperates besides oneself. In the punishment condition, when fellow players could punish noncooperative behavior by taking money from the free rider, most of the participants showed cooperative behavior. However, in the condition without consequences for free riders, cooperation depended on trait humility: Only people scoring high in humility behaved cooperatively, whereas people scoring low showed significantly less cooperative behavior (Hilbig et al., 2012). Thus, it can be argued that humble behavior is a reasonable indicator for a prosocial person, who is likely to be generous, forgiving, and cooperative in the future.

Associations of humility include prosociality and social bonding, as opposed to pride, which is associated with self-focus and superiority. Based on this reasoning, the present study tests the hypothesis that humility leads to a different perception than pride. 


\section{The current research}

Whereas humility conveys prosociality and the willingness to cooperate, pride is a rather competitive, status-emphasizing and self-focused expression associated with selfinterest (Tiedens et al., 2000; Tracy \& Robins, 2007b). Therefore, it seems plausible that people expect others (especially when hierarchically on the same level) to react less proudly and more humbly and also choose humble people over proud people when building social relationships (Kalokerinos et al., 2014; Wosinska et al., 1996). The stereotype content model, in turn, predicts higher perceived warmth when people are seen as potentially cooperating with the perceiver's goals, whereas people that are possibly interfering with these goals are evaluated as less warm (Fiske et al., 2002). With this said, it stands to reason that humility leads to more liking, or, in the words of the SCM, to higher perceived warmth, whereas pride lowers warmth and liking. Along with the preregistration (see Appendix), the two hypotheses for pride and humility are as follows:

- H1: Expressing pride leads to less warmth/less liking in comparison to a humble or a neutral reaction to success.

- H2: A humble expression leads to more warmth/more liking than both a neutral and a proud reaction to success.

Concerning competence, the second dimension of the stereotype content model, two relations are possible: It is either high/low like warmth or can be opposing to warmth. The latter is the case in what is called an ambivalent stereotype, when the two dimensions work in opposite directions. Here, when warmth is high, competence is low and vice versa. These ambivalent stereotypes are very typical patterns, especially when evaluating outgroups, as Fiske and her colleagues (2002) explain. The authors argue that the SCM applies both for 
groups and on an individual level. Thus, in line with ambivalent stereotyping, when pride leads to lower liking than humility, pride elicits higher competence perceptions than humility. Respective findings support this assumption of pride being the emotion used to convey success and status, and, therefore, trigger ascriptions of competence (Tiedens et al., 2000; Tracy \& Robins, 2007a). As an alternative reaction to success, the question arises whether humility is as capable as pride to convey such an assertion of success. Popular voices contradict traditional proverbs, as the introductory paragraph demonstrated. However, leadership is associated with competitiveness (Koenig et al., 2011), and agentic behavior elicits higher competence perceptions than less agentic behavior (Tiedens et al., 2000). Humility does not seem to convey such a message of status and success, which is something people consider when presenting themselves humbly to their friends but proudly towards strangers (Tice et al., 1995). Indeed, observers evaluate self-critics in comparison to selfenhancers as worse students or employees (Powers \& Zuroff, 1988). In this vein, humble reactions to success, triggering higher warmth and liking, should elicit lower perceptions of competence in comparison to pride. This reasoning results in the following two hypotheses concerning competence (see Appendix for the preregistration):

- H3: Pride leads to more perceived competence in comparison to a humble and a neutral reaction to success.

- H4: Expressing humility elicits less perceived competence than both a neutral and a proud reaction.

To investigate these hypotheses in the current study, participants learned about a more successful comparison standard, followed by the opponent's either proud, neutral, or humble reaction. Whereas it would be possible to experientially split humility or pride into their two subtypes, these two subtypes themselves entail certain appraisals, e.g. of self-esteem, agency 
or liking (Cheng, Tracy, \& Henrich, 2010; Tracy \& Robins, 2007b; Weidman et al., 2016). Therefore, an experimental differentiation can be reasonable when investigating these differences. But in real situations, expressions might more frequently be unspecified and ambivalent. The current study's aim was to leave the appraisal process to the participants so that they could build their own perceptions and interpretations. To uphold the ecological validity of the study, the proud and humble statements were, therefore, presented as single constructs. Apart from that, as appreciative humility is the reaction typically following success, it is plausibly more central in the actual research than its counterpart triggered by failure. Moreover, appreciative humility is also more strongly associated with the general terms of modesty and humility in Weidman et al.'s studies (2016), according to respective factor loadings. This speaks to the fact that appreciative humility is the prototypically stronger form of humility, which provides another reason why it was the type of humility induced in this study. Nevertheless, manipulation check scales determined the manifestation of both the two facets of humility and the two facets of pride (Tracy \& Robins, 2007b; Weidman et al., 2016) to track participants' interpretations.

In addition to the four scales that assessed the two appraisal dimensions warmth/liking and competence, one behavioral measure assessed perceived competence: Participants could invest their money on a possible subsequent victory of the humble, neutral, or proud opponent. The setting as a whole and especially the behavioral measure, offered the opportunity to create a real-world situation in which the opponent's reaction to success and the appraisal thereof affected the participants themselves. By retrieving scales together with a behavioral measure, the approach aimed to secure both the internal and external validity of the assessment. 


\section{Method}

Participants. Two hundred twenty people took part in the experiment that was conducted alternatingly in two laboratories of the Social Cognition Center Cologne on the campus of the University of Cologne. As stated in the preregistration, the goal was to collect data from a sample of 200 participants (see Appendix). However, the recruiting was more successful than expected, so that the required number was reached in four days (December $12-15,2016$ ). Several participants expressed their doubts about the cover story, which, according to the preregistration, would have led to their exclusion. As resources were sufficient, an additional 20 participants were invited on the last day. This decision was made before analyzing any data.

Participants were promised $2.50 €$ at the beginning of the experiment but received $5 €$ as a compensation for allegedly losing in the competition. Four participants had to be excluded due to technical mistakes when the computer or browser did not work properly. According to the preregistration, only participants who passed the funneled debriefing were included, meaning they believed the competition, their losing, and their opponent were real (excluded $n=17$ ). Thus, the final sample size was $N=199$, of which 100 participants were female, 97 male and two did not specify their gender. Participants were predominantly students $(93 \%)$; the mean age was $M=22.52(S D=3.49)$.

Procedure and material. Participants were invited to take part in a word building competition against one opponent. They would receive $2.50 €$ and had the prospect of winning $5 €$. All participants were seated in front of a monitor, where the experimenter started the experiment. The entire experiment lasted about 15 minutes (screenshots are available on https://osf.io/dvt53/?view_only=9f2a56b7e2d943ae9e3ddae1d4482ecb). 
After giving their consent, participants read the cover story containing the assertion that they took part in a project run at several universities. They indicated their gender and age to match them (so they were told) with a participant from a different university, who would be their opponent in the following word building competition. This alleged matching procedure was intended to introduce the competitor as a relevant comparison standard, suggesting a realistic chance of winning, so that nobody would attribute his or her later losing to external factors like age. During the matching procedure, as well as during subsequent alleged data exchange procedures, fake up- and download processes displayed on the screen lent the cover story credibility. The competitor's gender-neutral nickname used for all participants and across all conditions was jul_b. Having read the rules of the competition, the participants played three rounds, in each of them building as many words as possible from ten allotted letters. They were informed that the player earning the most points during these three rounds would win additional $2.50 €$, a total of $5 €$.

However, after round three, all participants read that they had lost the competition. They were then asked to shortly write down their feelings, as their opponent would do so, too. They would both get to read their reactions afterward. Unknown to them, the participants were randomly assigned to the three experimental conditions (proud [ $n=63]$, neutral $[n=69]$, or humble $[n=67])$, and their opponent's following statement differed according to condition. Just above their own reaction, the opponent's reaction appeared on the screen. The proud reaction was "cool, I won. I am proud of myself. curious how it will go on" ("cool, gewonnen. bin stolz auf mich. bin gespannt wie es weitergeht"), whereas the humble reaction was "cool, I won. but it was certainly close. curious how it will go on" ("cool, gewonnen. war aber bestimmt knapp. bin gespannt wie es weitergeht"). In the neutral condition the opponent only stated the last sentence: "curious how it will go on" ("bin gespannt wie es weitergeht”). The proud and humble statements resulted from the pretest explained below. To ensure that the participants processed jul_b's statement, the first rating of the opponent followed on the same 
page. As a means of manipulation check, participants completed scales to measure the two types of pride (Tracy \& Robins, 2007b) and the two types of humility (Weidman et al., 2016, see Table 1). These scales consisted of twenty adjectives that followed the sentence "jul_b is..." (“jul_b ist...”). Participants indicated their agreement on a scale of 1 (disagree extremely/ widerspreche völlig) to 5 (agree extremely/stimme völlig zu) to each of the descriptions. The scales consisted of four items for both authentic pride (Cronbach's $\alpha=.67$ ) and hubristic pride (Cronbach's $\alpha=.87$; see Table 1), adapted from Lange and Crusius (2015), who used the German translation of Tracy and Robin's scale (2007b) in their studies. Similarly, twelve items measured the two types of humility, six for appreciative humility (Cronbach's $\alpha=.80$ ) and another six for self-abasing humility (Cronbach's $\alpha=.75$; see Table

Table 1

Items of the manipulation check variables

\begin{tabular}{ll}
\hline Direct pride & jul_b reacted proudly to the victory. \\
& jul_b hat stolz auf den Sieg reagiert. \\
\hline Direct humility & jul_b reacted humbly to the victory. \\
& jul_b hat bescheiden auf den Sieg reagiert. \\
\hline Authentic pride & jul_b is... accomplished, confident, able, achieving \\
\hline Hubristic pride & jul_b. ist... erfolgreich, selbstsicher, fähig, leistungsfähig \\
\hline Appreciative humility & jul_b is... snobbish, pompous, arrogant, conceited \\
& jul_b ist... eingebildet, protzig, arrogant, selbstgefällig \\
\hline Self-abasing humility & jul_b is... meek, shameful, small, submissive, unimportant, worthless \\
jul_b ist... demütig, beschämt, klein, unterwürfig, unwichtig, wertlos
\end{tabular}

Note. Each one to be evaluated on a scale from 1 (disagree extremely/widerspreche völlig) to 5 (agree extremely/stimme völlig zu). Upper row English translation, second row original German wording. 
1). Weidman and his colleagues (2016) developed those items to differentiate between the two types of humility. For this study, they were translated into German. Afterward, another six items followed that measured the dependent variables general liking ( 3 items; Cronbach's $\alpha=.73$ ) and general competence (3 items; Cronbach's $\alpha=.85$; see Table 2). The participants again indicated their agreement to these statements from 1 (disagree extremely/widerspreche völlig) to 5 (agree extremely/stimme völlig zu). One additional item measured deservingness (“jul_b deserves the victory"/"jul_b hat den Sieg verdient").

Table 2

Items of the dependent variables

\begin{tabular}{ll}
\hline SCM warmth & $\begin{array}{l}\text { jul_b is... friendly, well-intentioned, trustworthy, warm, good-natured, sincere } \\
\text { jul_b ist... freundlich, wohlmeinend, vertrauenswürdig, warm, gutmütig, aufrichtig }\end{array}$ \\
\hline SCM competence & jul_b is... competent, confident, capable, efficient, intelligent, skillful \\
& jul_b ist... kompetent, selbstbewusst, fähig, effizient, intelligent, geschickt \\
\hline General liking & I do not like jul_b.; I have a positive attitude towards jul_b.; I think jul_b is a nice person. \\
& eine nette Person. \\
General & jul_b is good at such word games.; jul_b is competent.; jul_b has high verbal skills. \\
competence & jul_b ist gut in solchen Wortspielen.; jul_b ist kompetent.; jul_b hat hohe sprachliche \\
& Fähigkeiten.
\end{tabular}

Note. Each one to be evaluated on a scale from 1 (disagree extremely/widerspreche völlig) to 5 (agree extremely/stimme völlig zu). Upper row English translation, second row original German wording.

Then, the introduction of the behavioral variable followed. It consisted of a game that assessed the participants' estimation of their opponent's competence in a monetary way, similarly to how one would decide to invest in a humbly vs. proudly behaving employee, service provider, or the like. Participants read that they would get another opportunity to win 
additional $2.50 €$. To this end, they could invest any amount of their $2.50 €$ participationcompensation and bet on their former opponent winning in the next game against someone else. If the opponent won, their stake would double, otherwise they would lose it. The participants could indicate the amount of money they were willing to invest on a slide bar, ranging from $0 €$ to $2.50 €$. Afterward, they answered the last two scales, which took place, so the participants read, "as long as jul_b is playing the second game" ("so lange jul_b die zweite Runde spielt"). The first one of the two scales measured warmth and competence according to the stereotype content model (Fiske et al., 2002, see Table 2): “jul_b is...” (“jul_b ist...”) was followed by twelve adjectives, presented in random order. Six represented warmth (Cronbach's $\alpha=.88$ ), the other six adjectives represented competence (Cronbach's $\alpha=.87$; see Table 2). The second scale was a direct manipulation check, where participants again indicated their agreement on a five-point-scale (direct pride and direct humility; see Table 1). Two additional items read "jul_b reacted appropriately to the victory" (“jul_b hat angemessen auf den Sieg reagiert") and "jul_b reacted sincerely to the victory" ("jul_b hat aufrichtig auf den Sieg reagiert").

Finally, as a funneled debriefing, participants first openly stated if they had had any problems answering or understanding the survey, if something strange had attracted their attention, or if they wanted to comment anything concerning the experiment. Second, they should briefly summarize the intention of the study in their own words. The answers to these questions were coded according to belief or disbelief of the cover story (i.e. the competition, its result, or the competitor). Disbelief led to the exclusion from the later analysis $(n=17)$. At the end of the experiment, participants were debriefed that neither the competition nor the competitor had been real and that they had not lost. Everybody received $5 €$, the maximum amount he or she could have won in the study. 
Pretest. Nineteen participants took part in the online study (female: $n=6 ; M_{\text {age }}=33.84, S D$ age $=9.54)$ that was set up to choose one statement for the humble and proud conditions of the main study, respectively. After a brief description of the cover story of the main study, the participants read six different statements (see Appendix) in randomized order. The statements were chosen to represent the core constructs of either pride or humility in alternative ways, such as self- vs. other-focus and superiority vs. equity. However, as the definition of humility contains an accurate view of self, all statements comprised the same happy comment about the victory. The following scales corresponded to those used as manipulation check in the main study: Twenty adjectives for authentic and hubristic pride, and appreciative and selfabasing humility were presented with the initial sentence "Someone saying this, feels..." ("Eine Person, die so etwas sagt, fühlt sich..."). The direct items read: "The person reacts proudly" (“Die Person reagiert stolz”), "humbly" (“bescheiden”), "appropriately" ("angemessen"), and "sincerely" ("aufrichtig"). Two additional items ensured that the definitions of humility and pride were met, yet clearly distinct: "This person has a realistic view of self." ("Diese Peron hat ein realistisches Selbstbild.”) and "This reaction is selfcentered." ("Diese Reaktion ist selbstbezogen."). Participants evaluated all statements on the same 5-point Likert scale measuring agreement from 1 (disagree extremely/widerspreche völlig) to 5 (agree extremely/stimme völlig zu).

Only one statement for humility showed a significant difference (with an $\alpha$-level of $5 \%$ ) between direct pride and humility, $t(18)=-13.22, p<.001$ (see Appendix for results). Further analyses confirmed that this humility statement showed the highest appreciative humility and differed in most pride and humility types. They did not differ in authentic pride and appreciative humility, which are, according to Weidman et al. (2016) conceptually close, and in hubristic pride and self-abasing humility, which were similarly low across all humility statements. Therefore, the statement "I won! But it was certainly close." ("Gewonnen! War aber bestimmt knapp.”) was chosen. Concerning the proud condition, two statements showed 
a significant difference between directly measured pride and humility, and similar results in the other measures. Eventually, the final statement stood out due to lower humility scores and higher appropriateness and sincerity scores. So, "I won! I am proud of myself.” (“Gewonnen! Bin stolz auf mich.") was chosen for the pride condition.

The two final statements of humility and pride significantly differed in perceived humility, $t(18)=-7.57, p<.001$, pride, $t(18)=6.60, p<.001$, and self-centeredness, $t(18)=$ $10.47, p<.001$. In addition, they did not differ in perceived appropriateness, $t(18)=-1.58, p=$ .130 , sincerity, $t(18)=0.19, p=.853$, and accurate view of self, $t(18)=-1.16, p=.262$, which, otherwise, could have impaired the effect of the two conditions differently.

Furthermore, participants repeatedly complained about the introductory sentence "Someone saying this, feels..." ("Eine Person, die so etwas sagt, fühlt sich..."). They lamented that they could not assess or know how the other person feels and felt very insecure answering the question. Originally, these scales were developed to measure how oneself feels and read "I feel..."/’Ich fühle mich..." (Lange \& Crusius, 2015; Weidman et al., 2016). They were not developed to assess how one thinks another observed person feels. That is why the wording was adapted in the pretest. Apparently, this adaption confused the participants. To make the items as easy to understand as possible, the sentence simply read "jul_b is..." (“jul_b ist...") in the main study. Note that such alteration of scales may change the meaning of the scales in subtle ways. This issue will be discussed later.

Concerning the final statements, the design of the study required marginal modifications. Firstly, a neutral condition should ensure that effects for both humble and proud condition could be detectable separately. The sentence "curious, how it will go on" ("bin gespannt wie es weitergeht") does not bear any considerable emotional information. Therefore, it was intended to serve as the neutral condition and also not to change the pretested statements in a crucial way. Secondly, in a test run with several students, they found 
the comments to be too formal and thus undermined the credibility of the cover story. For this reason, a "cool" was added at the beginning, and the statements were put in lower case to adapt to a younger, informal audience.

\section{Results}

The following paragraph contains preregistered and exploratory analyses. In the preregistration, the main approach included the four hypotheses as well as their analyses. The manipulation check and correlations were registered as secondary analyses. The results presented in the Exploration paragraph are subsequent calculations that go beyond the registration. Nevertheless, they are considered necessary to understand the results and to underpin their interpretation. The preregistration can be found on http://aspredicted.org/blind.php/?x=if69i9. All data and calculations are available on https://osf.io/dvt53/?view_only=9f2a56b7e2d943ae9e3ddae1d4482ecb (see Appendix).

Manipulation check. A manipulation check determined the efficiency of the manipulation. Therefore, mean values were computed for the manipulation check measures: authentic pride and hubristic pride as well as appreciative humility and self-abasing humility.

ANOVAs analyzed each manipulation check variable. The three conditions served as between factors and significance levels were set at $\alpha=5 \%$. Both direct pride, $F(2,196)=$ $58.39, p<.001, \eta_{\mathrm{p}}{ }^{2}=.373$, and direct humility, $F(2,196)=96.58, p<.001, \eta_{\mathrm{p}}{ }^{2}=.272$, differed significantly between conditions (for descriptive data see Table 3). However, posthoc analyses with Bonferroni correction showed that in both cases the humble condition did not differ from the neutral condition, direct pride: $p=.349$, direct humility: $p=.560$., which deviates from the preregistered assumptions. Proud and neutral as well as proud and humble condition differed significantly, all: $p<.001$. 
Table 3

Mean values and SD of manipulation check variables depending on the conditions

\begin{tabular}{|c|c|c|c|c|c|c|c|c|c|c|c|c|c|c|c|c|}
\hline \multirow[b]{2}{*}{ Condit. } & \multicolumn{2}{|c|}{$\begin{array}{l}\text { Direct } \\
\text { pride }\end{array}$} & \multicolumn{2}{|c|}{$\begin{array}{l}\text { Direct } \\
\text { humility }\end{array}$} & \multicolumn{2}{|c|}{$\begin{array}{l}\text { Authentic } \\
\text { pride }\end{array}$} & \multicolumn{2}{|c|}{$\begin{array}{c}\text { Hubristic } \\
\text { pride }\end{array}$} & \multicolumn{2}{|c|}{$\begin{array}{l}\text { Appreciat. } \\
\text { humility }\end{array}$} & \multicolumn{2}{|c|}{$\begin{array}{l}\text { S.-Abasing } \\
\text { humility }\end{array}$} & \multicolumn{2}{|c|}{$\begin{array}{l}\text { Appropri- } \\
\text { ateness }\end{array}$} & \multicolumn{2}{|c|}{ Sincerity } \\
\hline & $M$ & $S D$ & $M$ & $S D$ & $M$ & $S D$ & $M$ & $S D$ & $M$ & $S D$ & $M$ & $S D$ & $M$ & $S D$ & $M$ & $S D$ \\
\hline humble & 3.06 & 0.92 & 4.12 & 0.96 & 3.62 & 0.58 & 1.60 & 0.61 & 3.61 & 0.56 & 1.87 & 0.63 & 4.30 & 0.89 & 4.01 & 0.83 \\
\hline neutral & 2.80 & 1.11 & 3.88 & 1.08 & 3.67 & 0.60 & 1.94 & 0.82 & 3.12 & 0.66 & 1.95 & 0.67 & 3.96 & 0.90 & 3.65 & 0.90 \\
\hline proud & 4.51 & 0.86 & 2.67 & 1.06 & 3.73 & 0.55 & 2.65 & 0.95 & 2.86 & 0.60 & 1.94 & 0.63 & 3.83 & 1.02 & 3.84 & 0.87 \\
\hline
\end{tabular}

Note. $n_{\text {humble }}=67, n_{\text {neutral }}=69, n_{\text {proud }}=63$

In the following, sincerity did not differ between conditions (although closely), $F(2$, 196) $=2.98, p=.053, \eta_{\mathrm{p}}^{2}=.030$. Post-hoc analyses showed that, unexpectedly, sincerity was perceived higher in the humble than in the neutral condition (although, again, closely), $p=$ .047 (see Table 3). But neither the proud and neutral, $p=.635$, nor the proud and humble condition differed in sincerity, $p=.764$. Differences between conditions emerged for appropriateness, $F(2,196)=4.47, p=.013, \eta_{\mathrm{p}}{ }^{2}=.044$. A Bonferroni corrected post-hoc analysis provided more differentiated information: Appropriateness was lower in the proud than in the humble condition, $p=.013$, contradicting the findings from the pretest. Neither of the other comparisons yielded any significance. The significant differences run counter to the preregistered expectation of similar adequacy of all conditions.

Further, the effects of the conditions on the four scales, measuring the two types of pride and the two types of humility, were analyzed (see Table 3). Despite the preregistration that expected differences between all conditions in all four scales, authentic pride was very high across all conditions and its perception did not show any differences, $F(2,196)=0.55, p$ $=.578, \eta_{\mathrm{p}}^{2}=.006$. Self-abasing humility was perceived extremely low across all conditions, and also did not differ across conditions, $F(2,196)=0.33, p=.721, \eta_{\mathrm{p}}{ }^{2}=.003$. However, hubristic pride differed between condition, $F(2,196)=28.84, p<.001, \eta_{\mathrm{p}}{ }^{2}=.227$, as well as 
appreciative humility, $F(2,196)=25.87, p<.001, \eta_{\mathrm{p}}^{2}=.209$. The conducted Bonferroni pairwise comparisons found the expected pattern for hubristic pride, such that its perception was higher in the proud than the neutral condition, $p<.001$, and lower in the humble than the neutral condition, $p=.042$. The opposite pattern emerged for appreciative humility with higher means in the humble compared to the neutral condition, $p<.001$, and lower means in the proud than in the neutral condition, $p=.047$.

As an additional, exploratory analysis, the correlation among the variables of the manipulation check was of interest. The two direct questions asking to what extent the expressed statements were proud and to what extent they were humble correlated negatively with each other, $r(197)=-.41, p<.001$, supporting the fact that two different constructs were measured. In addition, the direct pride question showed significant relations to both authentic pride, $r(197)=.19, p=.008$, and hubristic pride, $r(197)=.29, p<.001$, in line with the assumption that these two scales represent two parts of pride. In the same vein, appreciative humility showed a high correlation with the direct humility item, $r(197)=.47, p<.001$. However, self-abasing humility did not correlate with it significantly, $r(197)=-.06, p=.398$, nor did self-abasing humility correlate with appreciative humility, $r(197)=-.02, p=.741$. To the contrary, self-abasing humility showed a negative correlation with authentic pride, $r(197)$ $=-.20, p=.005$, and a strong relation to hubristic pride, $r(197)=.54, p<.001$. This suggests a further investigation on the status of self-abasing humility.

Dependent variables. To calculate the influence of the reaction on the perception of warmth/liking and competence, mean values for the four scales were calculated across the items of each scale: SCM warmth and SCM competence as well as general competence and general liking.

All calculations are available on OSF and the main approach was preregistered on aspredicted.org (see Appendix). According to this preregistration, an overall MANOVA on all 
dependent variables and ANOVAs for each of them were conducted using the three conditions as between-factor. Most dependent variables visually met the preconditions of a normal distribution (despite deviating from it in the Shapiro-Wilk-test, see Table 4). Only the invested money variable passed neither of the tests, as a disproportional number of participants chose the most extreme options: $14 \%$ did not bet any and $22 \%$ all their money. Because the F-test is robust against light violations of normality (Field, 2009), the conditional groups were of equal number, and the assumptions of homoscedasticity were mainly met (see Table 4), a MANOVA and several ANOVAs were performed on the dependent variables. For all of the following analyses, a significance level of $\alpha=5 \%$ was set.

Table 4

Tests conducted on dependent variables to check the conditions necessary for ANOVAs

\begin{tabular}{lccccc} 
& \multicolumn{3}{c}{ Test for normality } & \multicolumn{2}{c}{ Test for homoscedasticity } \\
\cline { 2 - 6 } Dependent variables & \multicolumn{2}{c}{ Shapiro-Wilks-Test } & Visual & $F(2,196)$ & $P$ \\
\hline SCM warmth & $W$ & $P$ & & 0.03 & 0.971 \\
SCM competence & 0.97 & $<0.001$ & norm. & 0.29 & 0.752 \\
General liking & 0.96 & $<0.001$ & norm. & 5.77 & 0.004 \\
General competence & 0.93 & $<0.001$ & norm. & 0.46 & 0.631 \\
Money invested & 0.95 & $<0.001$ & norm. & 0.41 & 0.667
\end{tabular}

The MANOVA indicated significant differences between the dependent variables concerning the three conditions, $F(10,386)=6.08, p<.001, \eta_{\mathrm{p}}^{2}=.136$ (see Table 5 for descriptive values). In the following, analyses of variance were conducted for each of the five dependent variables. Firstly, two ANOVAs tested $\mathrm{H} 1$ and $\mathrm{H} 2$, which stated that pride led to less warmth/liking and humility to more warmth/liking than the neutral condition. Therefore, the scale assessing warmth, derived from the Stereotype Content Model, was analyzed. An 
Table 5

Mean values and SD of the dependent variables depending on condition

\begin{tabular}{lcccccccccc} 
& \multicolumn{2}{c}{$\begin{array}{c}\text { SCM } \\
\text { competence }\end{array}$} & \multicolumn{2}{c}{$\begin{array}{c}\text { General } \\
\text { competence }\end{array}$} & \multicolumn{2}{c}{$\begin{array}{c}\text { SCM } \\
\text { warmth }\end{array}$} & \multicolumn{2}{c}{$\begin{array}{c}\text { General } \\
\text { liking }\end{array}$} & \multicolumn{2}{c}{$\begin{array}{c}\text { Invested } \\
\text { money }\end{array}$} \\
\cline { 2 - 12 } Condition & $M$ & $S D$ & $M$ & $S D$ & $M$ & $S D$ & $M$ & $S D$ & $M$ & $S D$ \\
\hline humble & 3.66 & 0.62 & 3.85 & 0.75 & 3.70 & 0.55 & 4.23 & 0.53 & 44.70 & 34.74 \\
neutral & 3.75 & 0.53 & 3.93 & 0.73 & 3.40 & 0.61 & 3.95 & 0.66 & 51.46 & 36.77 \\
proud & 3.73 & 0.50 & 3.69 & 0.68 & 3.13 & 0.57 & 3.77 & 0.79 & 53.13 & 33.92
\end{tabular}

ANOVA showed that warmth differed in the three conditions, $F(2,196)=15.54, p<.001, \eta_{\mathrm{p}}{ }^{2}$ $=.137$. Along with the registered hypotheses, the calculated contrasts showed that pride led to less perceived warmth than the neutral reaction, $F(1,196)=21.97, p<.001, \eta_{\mathrm{p}}{ }^{2}=.101$, and humility led to more perceived warmth than the neutral reaction, $F(1,196)=25.01, p<.001$, $\eta_{\mathrm{p}}^{2}=.113$ (see Figure 1). The variable general liking mirrored the SCM variable warmth: The ANOVA revealed a significant difference between conditions, $F(2,196)=8.18, p<.001, \eta_{\mathrm{p}}^{2}$ $=.077$. Again, the calculated contrasts showed that pride led to lower perceived liking, $F(1$,
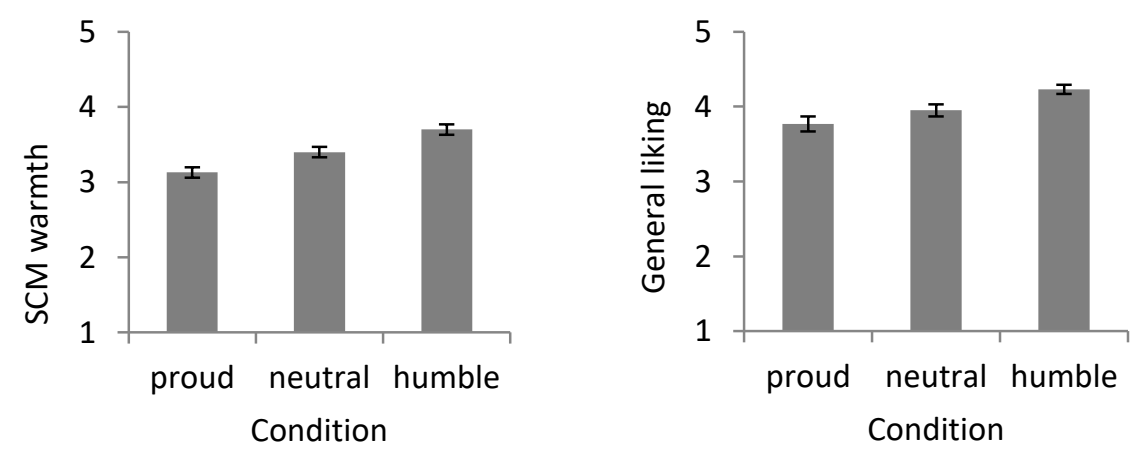

Figure 1. Mean SCM values of SCM warmth (Fiske et al., 2002) and general liking (Lange \& Crusius, 2015) depending on condition $\left(n_{\text {proud }}=63, n_{\text {neutral }}=69, n_{\text {humble }}=67\right)$. Error bars indicate the standard error of the mean. 
196) $=10.35, p=.002, \eta_{\mathrm{p}}{ }^{2}=.050$, whereas humility led to higher perceived liking than the neutral reaction, $F(1,196)=14.12, p<.001, \eta_{\mathrm{p}}{ }^{2}=.067$ (see Figure 1$)$. These results support $\mathrm{H} 1$ and $\mathrm{H} 2$ about warmth/liking.

Secondly, the hypotheses concerning competence were addressed, expecting pride to lead to more (H3) and humility to lead to less perceived competence than the neutral condition (H4). Contrary to these expectations, the SCM scale assessing competence did not show any significant difference across the three conditions, $F(2,196)=0.47, p=.628, \eta_{\mathrm{p}}{ }^{2}=$ .005. The calculated contrasts confirmed: SCM competence yielded neither a difference between pride and neutral reaction, $F(1,196)=0.09, p=.769, \eta_{\mathrm{p}}^{2}<.001$, nor between humility and neutral reaction, $F(1,196)=0.89, p=.348, \eta_{\mathrm{p}}{ }^{2}=.004$ (see Figure 2 ). Similar to competence, general competence did not differ between the three conditions, $F(2,196)=$ $1.94, p=.146, \eta_{\mathrm{p}}{ }^{2}=.077$, although the difference between proud and neutral reaction closely missed significance, $F(1,196)=3.37, p=.068, \eta_{\mathrm{p}}^{2}=.017$. Remarkably, on a descriptive level, pride led to even lower competence perceptions than the neutral reaction. Humility,
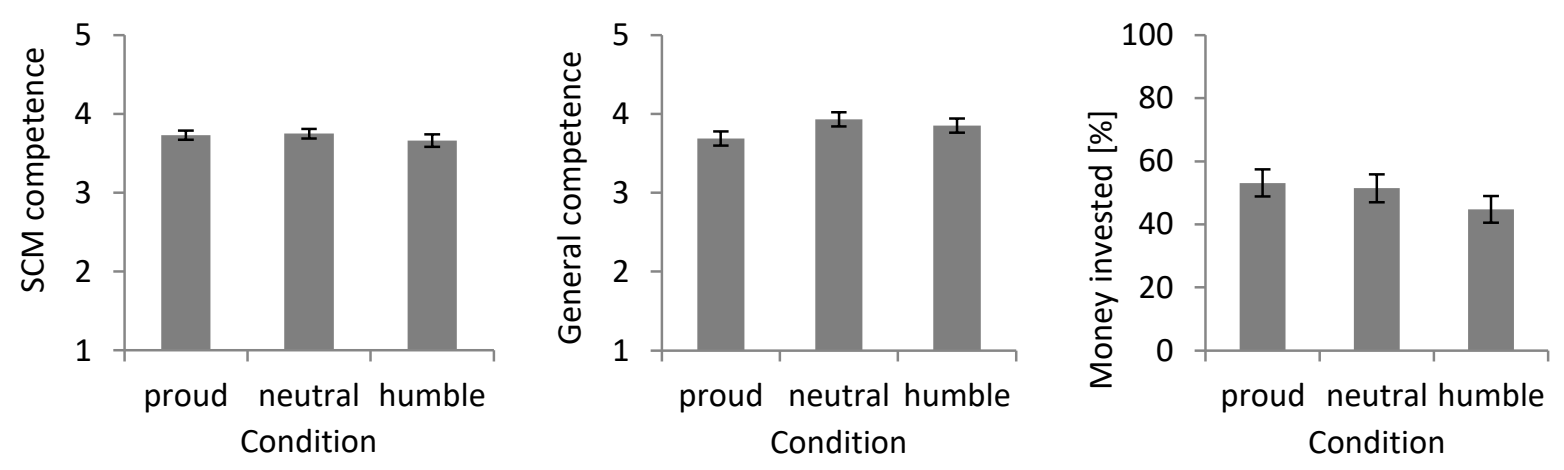

Figure 2. Mean values of SCM competence (Fiske et al., 2002) and general competence depending on conditions, measured on a 5-point Likert-scale. Money bet measured as investment from 0 to $2.50 €$, here depicted as $\%$-value, depending on condition $\left(n_{\text {proud }}=63\right.$, $\left.n_{\text {neutral }}=69, n_{\text {humble }}=67\right)$. Error bars indicate the standard error of the mean. 
however, led to just as much perceived competence as the neutral reaction, $F(1,196)=0.11, p$ $=.741, \eta_{\mathrm{p}}^{2}=.001$ (see Table 5). These results, which are mapped in Figure 2, contradict the preregistered $\mathrm{H} 3$ and $\mathrm{H} 4$. Finally, an ANOVA analyzed the invested money variable, which depicted how much the participants had been willing to bet on their opponent winning. It should serve as an applied measure of competence and showed no difference between conditions, $F(2,196)=1.06, p=.348, \eta_{\mathrm{p}}^{2}=.011$ (see Figure 2). As before, planned contrasts showed neither a significant difference between humility and the neutral condition, $F(1,196)$ $=1.25, p=.265, \eta_{\mathrm{p}}{ }^{2}=.006$, nor between pride and the neutral condition, $F(1,196)=0.07, p=$ $.787, \eta_{\mathrm{p}}{ }^{2}<.001$. Even contrasting pride and humility revealed no significant difference, $F(1$, $196)=1.86, p=.174, \eta_{\mathrm{p}}{ }^{2}=.009$. Even though, on a descriptive level, the expected pattern emerged, the other competence variables did not support this trend. The fact that all three competence measures showed similar effects indicates their construct validity. The three scales demonstrate that competence was appraised as being high but not different across conditions.

According to the preregistered secondary analyses, correlational analyses should assess the validity of the scales. Liking and warmth correlated highly, $r(197)=.52, p<.001$, supporting the assumption that they measured the same construct. Likewise, generally measured competence and SCM competence were highly correlated, $r(197)=.54, p<.001$. However, the two scales of the SCM, competence and warmth, correlated to a similar extent, $r(197)=.56, p<.001$. Likewise, the general competence scale showed high associations with both general liking, $r(197)=.38, p<.001$, and SCM warmth, $r(197)=.39, p<.001$. Intended as an applied means to depict competence, the invested money variable was of interest as a measure of construct validity. Invested money correlated with SCM competence, $r(197)=.22$, $p=.002$, but did not with general competence, $r(197)=.13, p=.077$. Contrary to the other competence measures but in line with the expectations, invested money showed neither a significant relation to warmth, $r(197)=.09, p=.190$, nor to liking, $r(197)=.08, p=.262$. 
Exploration. There are several open questions and untested relations, which possibly provide insights into the effects of humility and pride on appraisals of competence and liking. It is noteworthy that the following analyses go beyond the preregistration and serve as an additional exploration of the data (see Appendix).

First, the issue of a possible confounding of appropriateness and sincerity with the effect of the conditions on the dependent variables was addressed. ANCOVAs served as a means to control for appropriateness and sincerity while investigating the effect of the conditions. Appropriateness did influence the dependent variables (see Table 6). However, both general liking, $F(2,195)=4.60, p=.011, \eta_{\mathrm{p}}{ }^{2}=.045$, and also SCM warmth, $F(2,195)=$ $10.84, p<.001, \eta_{\mathrm{p}}{ }^{2}=.100$, showed the same pattern as in the main analysis, albeit with weaker effects,. The effects also remained insignificant for general competence, $F(2,195)=$ $1.71, p=.183, \eta_{\mathrm{p}}{ }^{2}=.017$, and for SCM competence, $F(2,195)=3.01, p=.052, \eta_{\mathrm{p}}{ }^{2}=.030$. On a descriptive level, SCM competence was lowest in the humble and highest in the proud condition. Similar findings emerged for sincerity: Although its influence was high on the dependent variables (see Table 6), the effects of pride and humility stayed similar to before. General liking showed the expected pattern, $F(2,195)=7.30, p=.001, \eta_{\mathrm{p}}^{2}=.030$, and so did

Table 6

Effects of the covariates sincerity and appropriateness on the dependent variables in two separate ANCOVAs

\begin{tabular}{lcccrcc} 
& \multicolumn{3}{c}{ Sincerity } & \multicolumn{3}{c}{ Appropriateness } \\
\cline { 2 - 7 } DVs & $F(1,195)$ & $p$ & $\eta_{\mathrm{p}}{ }^{2}$ & $F(1,195)$ & $p$ & $\eta_{\mathrm{p}}{ }^{2}$ \\
\hline General liking & 21.17 & $<.001$ & .098 & 39.34 & $<.001$ & .168 \\
General competence & 16.49 & $<.001$ & .078 & 9.27 & .003 & .045 \\
SCM warmth & 49.59 & $<.001$ & .203 & 63.91 & $<.001$ & .247 \\
SCM competence & 41.14 & $<.001$ & .174 & 49.20 & $<.001$ & .201
\end{tabular}


warmth, $F(2,195)=16.10, p<.001, \eta_{\mathrm{p}}^{2}=.147$. Again, neither general competence, $F(2,195)$ $=2.88, p=.059, \eta_{\mathrm{p}}{ }^{2}=.029$, nor SCM competence differed across condition, $F(2,195)=2.24$, $p=.109, \eta_{\mathrm{p}}{ }^{2}=.022$. It should be noted, however, that on a descriptive level the effect of pride on competence decreased. That is, both competence measures were highest in the neutral and lower for proud and humble condition, when controlled for sincerity.

A second question related to the invested money variable. As it was not normally distributed but had a W-shape, the question raised whether an analyses other than an ANOVA might uncover hidden effects. However, neither (a) a chi-square test after a median split of the money variable $(M d n=42), \chi^{2}(2)=1.19, p=.55$ (see Table 7), nor (b) an ANOVA with a subset of data $(n=129)$, excluding participants, who set all or none of their money, yielded significance, $F(2,126)=0.38, p=.685, \eta_{\mathrm{p}}{ }^{2}=.006$. Also (c), comparing "investors" to "noninvestors", did not show any significant results: Neither those who invested everything (n $=45)$ vs. less than everything $(n=154), \chi^{2}(2)=1.37, p=.503$, nor those who invested nothing $(n=27)$ vs. something $(n=172), \chi^{2}(2)=1.32, p=.518$, differed significantly (see Table 7). These results demonstrated that the absent effect of humility/pride on money invested was not due to the variable's distribution problems. More so, even when transforming and converting the variable, the corresponding tests found no significant effects. However, it has to be noted that, in total numbers, the participants invested higher amounts

Table 7

Number of investors depending on condition, split along different thresholds

\begin{tabular}{lcccccc} 
Split along: & \multicolumn{2}{c}{ Median } & \multicolumn{2}{c}{$100 \%$} & \multicolumn{2}{c}{$0 \%$} \\
\hline Condition & $n_{\text {more }}$ & $n_{\text {less }}$ & $n_{\text {everything }}$ & $n_{\text {less }}$ & $n_{\text {something }}$ & $n_{\text {nothing }}$ \\
\hline proud & 36 & 27 & 15 & 48 & 57 & 6 \\
neutral & 35 & 34 & 18 & 51 & 58 & 11 \\
humble & 32 & 35 & 12 & 55 & 57 & 10
\end{tabular}


and more often into proudly than into humbly reacting opponents (see Table 7).

Another relation of interest is the effect of perceived humility/pride on competence and warmth/liking. The manipulation check ratings provide the opportunity to investigate the participants' perception of their opponents' humility and pride in a within-design. Thus, the four dependent variables of liking and competence were correlated with the six manipulation check measures: direct humility and direct pride, as well as authentic pride, hubristic pride, appreciative humility, and self-abasing humility. Significant and strong correlations emerged for nearly all of them (see Table 8). Moreover, both warmth/liking and competence were related positively to authentic pride and appreciative humility, but negatively to hubristic pride and self-abasing humility. Thus, the more desirably connoted constructs contrasted the less desirable constructs - they were more similar across pride and humility than within them. A striking pattern emerged concerning the strength of correlations: Authentic pride showed highest correlations with competence. On the contrary, appreciative humility as well as direct humility showed similarly high correlations—but with warmth/liking (see Table 8). These higher correlations hint to $\mathrm{H} 2$ and $\mathrm{H} 3$ : Humility perceptions more strongly influence warmth/liking and pride perceptions more strongly influence competence. Nevertheless, it can

Table 8

Correlation of dependent and manipulation check variables

\begin{tabular}{lccccccc} 
& Authentic $\mathrm{p}$. & Hubristic $\mathrm{p}$. & Appreciat. h. & Self-abas. h. & Direct $\mathrm{p}$. & Direct h. \\
\cline { 2 - 7 } SCM warmth & $0.34 * *$ & $-0.42 * *$ & $0.56 * *$ & $-0.19 *$ & -0.12 & $0.51 * *$ \\
SCM competence & $0.59 * *$ & $-0.20 *$ & $0.23 *$ & $-0.27 * *$ & $0.15 *$ & $0.24 *$ \\
General liking & $0.22 *$ & $-0.52 * *$ & $0.49 * *$ & $-0.28 * *$ & -0.11 & $0.44 * *$ \\
General compet. & $0.48 * *$ & $-0.27 * *$ & $0.30 * *$ & $-0.26 * *$ & -0.03 & $0.21 *$
\end{tabular}

Note. $\mathrm{p} .=$ pride, $\mathrm{h} .=$ humility; $* *: p<.001, *: p<.05$ 
be noted that hubristic pride resembles - although negatively — appreciative humility more closely than authentic pride.

Another question came up regarding the high correlation of the dependent variables in this study. As described earlier, this concerned high relations of SCM competence and warmth, and also general competence with strong relations to both general liking and SCM warmth. These strong interdependencies raise the issue that, when talking about the effect of the reactions on warmth/liking, perceived competence has a huge influence on warmth/liking at the same time. And vice versa: When talking about perceived competence, its interplay with warmth/liking also has to be considered. ANCOVAs can help to exclude such influences by using the respective other variable as a covariate. On one hand, such an approach offers the opportunity to statistically control for the influence of one construct and to calculate the bare effect of the condition on the other one. On the other hand, this is a merely theoretical approach, as such high correlations indicate that the two constructs are interdependent and operate together, no matter what a statistician calculates. It is important to remember that competence without warmth/liking is no longer the same construct, but a residual of competence without its inherent part of warmth/liking — and the other way round (Field, 2009; Miller \& Chapman, 2001). Nevertheless, in the conducted ANCOVA, the effect of the conditions on warmth when controlling for SCM competence mirrored those from the main analysis, which supported H1 and H2 (see Table 9). Higher warmth was assessed for humbly reacting opponents compared to neutrally reacting opponents, lower warmth for proudly than for neutrally reacting opponents. The general liking variable showed equal results, although neutral and proud condition did not differ in liking when controlling for general competence (see Table 9). Concerning competence, the ANCOVA showed a significant effect of SCM warmth on SCM competence, $F(1,195)=127.48, p<.001, \eta_{\mathrm{p}}^{2}=.395$, and a significant effect of condition on SCM competence when controlling for SCM warmth, $F(2,195)=13.14, p<$ $.001, \eta_{\mathrm{p}}{ }^{2}=.119$ (see Figure 3). Moreover, the effect size hinted at a moderate effect of 
Table 9

Results of two ANCOVAs analyzing the influence of the conditions (humble, neutral, and proud) on warmth and liking when controlled for competence

\begin{tabular}{|c|c|c|c|c|c|}
\hline & & $\mathrm{df}$ & $F(d f, 195)$ & $p$ & Partial $\eta^{2}$ \\
\hline \multicolumn{6}{|l|}{ DV: SCM warmth } \\
\hline & Covariate: SCM competence & 1 & 127.48 & $<.001$ & .395 \\
\hline & Effect of conditions & 2 & 30.08 & $<.001$ & .236 \\
\hline & Contrast: humble to neutral & 1 & 21.67 & $<.001$ & .100 \\
\hline & Contrast: proud to neutral & 1 & 10.05 & .002 & .049 \\
\hline \multicolumn{6}{|l|}{ DV: General liking } \\
\hline & Covariate: General competence & 1 & 33.28 & $<.001$ & .146 \\
\hline & Effect of conditions & 2 & 7.99 & $<.001$ & .076 \\
\hline & Contrast: humble to neutral & 1 & 8.76 & .003 & .043 \\
\hline & Contrast: proud to neutral & 1 & 0.82 & .365 & .004 \\
\hline
\end{tabular}

condition on competence when warmth was controlled. When warmth was statistically held constant, planned contrasts showed that humility led to lower perceived competence than the neutral condition, $F(1,195)=12.71, p<.001, \eta_{\mathrm{p}}{ }^{2}=.061$, whereas the proud compared to the neutral reaction closely missed significance, $F(1,195)=3.28, p=.072, \eta_{\mathrm{p}}{ }^{2}=.017$ (see Figure 3). The previously mostly similar results of SCM variables and general variables showed different results here. General liking influenced general competence, $F(1,195)=33.28, p<$ $.001, \eta_{\mathrm{p}}{ }^{2}=.146$, but when controlling for liking, general competence did not show differences in conditions, $F(2,195)=1.80, p=.169, \eta_{\mathrm{p}}{ }^{2}=.018$. Neither the difference between humble and neutral condition, $F(1,195)=3.08, p=.081, \eta_{\mathrm{p}}{ }^{2}=.015$, nor between proud and neutral condition yielded significance for general competence, $F(1,195)=2.08, p=.151, \eta_{\mathrm{p}}^{2}=.011$. Moreover, on a descriptive level, the neutrally reacting opponents were perceived as being slightly more competent than both proud and humble opponents when liking was held constant (see Figure 3). This result of general competence contradicts both H3 and H4. Invested money, however, showed the expected pattern on a descriptive level when warmth was excluded. In the ANCOVA, warmth had a significant influence on money invested, $F(1$, 

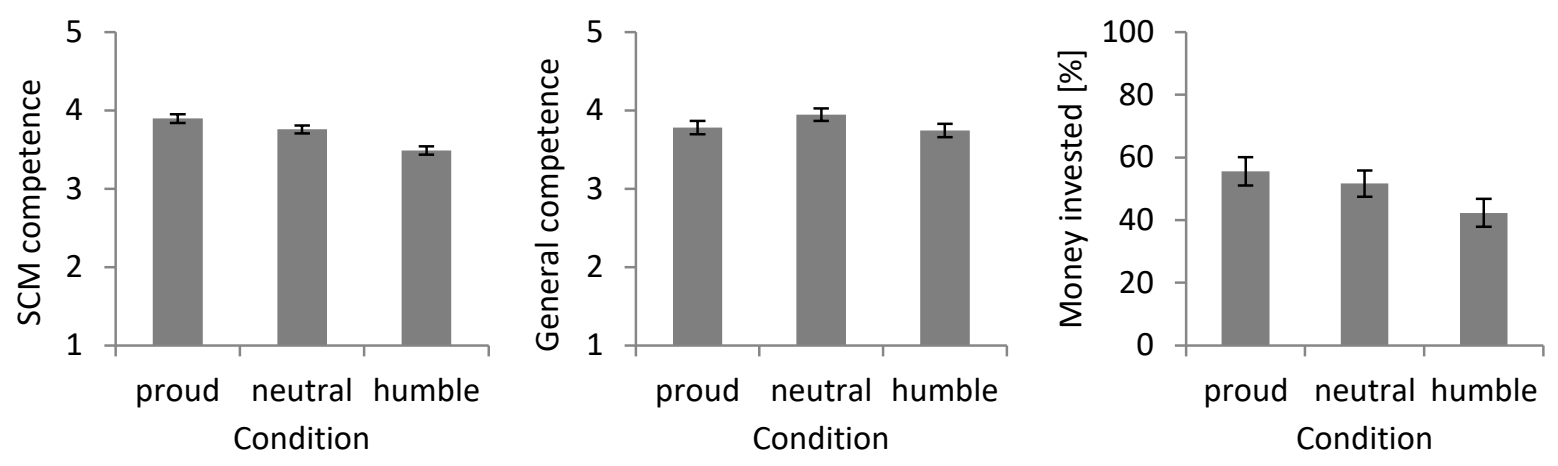

Figure 3. Mean values of SCM competence (Fiske et al., 2002) with SCM warmth hold constant, $M_{\text {warmth }}=3.42$; mean value of general competence with general liking hold constant, $M_{\text {liking }}=3.99 ;$ mean value of invested money with warmth hold constant, $M_{\text {warmth }}=3.42$; depending on condition ( $n_{\text {proud }}=63, n_{\text {neutral }}=69, n_{\text {humble }}=67$ ). First two variables measured agreement on a 5-point Likert-scale. Error bars indicate the standard error of the mean.

$195)=3.94, p=.049, \eta_{\mathrm{p}}^{2}=.020$. Here, however, the effect of conditions missed significance when warmth was held constant, $F(2,195)=2.17, p=.117, \eta_{\mathrm{p}}^{2}=.022$. Although planned contrasts between humble and neutral, $F(1,195)=2.33, p=.129, \eta_{\mathrm{p}}{ }^{2}=.012$, or proud and neutral condition, $F(1,195)=0.40, p=.529, \eta_{\mathrm{p}}^{2}=.002$, did not yield any significance, directly comparing proud and humble condition showed a significant difference of invested money, $F(1,195)=4.04, p=.046, \eta_{\mathrm{p}}{ }^{2}=.020$ (see Figure 3 ), with a small but perceivable effect size. Controlling for liking yielded descriptively similar but no significant effects ${ }^{2}$.

Taken together, the hypotheses about warmth/liking were confirmed, showing that pride led to less liking, whereas humility resulted in more liking and warmth than a neutral

\footnotetext{
${ }^{2}$ In the ANCOVA, liking had no significant influence on money, $F(1,195)=2.52, p=.114, \eta_{p}{ }^{2}=.013$. Controlling for liking, the conditions yielded no significant effect on invested money, $F(2,195)=1.69, p=.187, \eta_{p}^{2}=.017$. As the contrasts showed, the difference between humility and pride closely missed significance, $F(1,195)=$ $3.01, p=.081, \eta_{\mathrm{p}}{ }^{2}=.016$. Nevertheless, the descriptive pattern resembled the one for money invested when warmth was excluded.
} 
reaction ( $\mathrm{H} 1$ and $\mathrm{H} 2)$. However, the results did not support the hypotheses of competence (H3 and H4). Whether a proud, neutral, or humble reaction to success, they all led to similarly high ascriptions of competence. The behavioral measure of competence, which assessed how much money participants bet on another victory of their opponent, did not show any difference between conditions either. Conducted exploratory analyses mainly supported the findings of the main analysis, although correlational analyses, as well as ANCOVAs, offered small hints at the competence assumption.

\section{Discussion}

The intention of the study was to investigate the benefits and costs of humility or, more specifically, to determine the effect of a humble vs. a proud reaction to appraisals of warmth/liking and competence. Whereas popular media praise humility as an attitude toward life, which promotes success and career, pride is the emotion commonly associated with status and achievement. This discrepancy cumulates in the - originally German — proverb, stating that humility might be graceful but hinders one from being truly successful. The question emerged: which is the right path to take, pride or humility? What are the underlying appraisals that are evoked by either pride or humility? Based on existing research about pride and humility, four hypotheses concerning their effect on liking and competence appraisals were developed and tested in the study.

The first hypothesis expected pride to lead to less warmth/liking compared to a neutral or humble reaction to success. The current results confirmed both this hypothesis and the second, complementary hypothesis, expecting humility to lead to more warmth/liking than a neutral or proud reaction. The core of these hypotheses was the assumption that pride expresses self-interest (Horberg et al., 2013), whereas humility conveys prosociality and 
social bonding (Hilbig et al., 2012; Weidman et al., 2016). The resulting high effect sizes boldly support the strength of the effect of humility (vs. pride), which elicits high (vs. low) feelings of warmth/liking towards the expressing person. The effects not only proved to be strong but also robust: With or without the influence of sincerity or appropriateness, the effect of emotional expression on warmth/liking emerged solidly. And although the results changed for liking, warmth showed the expected pattern when controlling for competence.

The third and fourth hypotheses referred to competence, which was expected to be higher for a proud and lower for a humble expression compared to a neutral one. These hypotheses were based on the assumption that pride is a status-expressing emotion and conveys a message of achievement and success. Moreover, according to an effect called ambivalent stereotyping, low warmth perceptions correlate with high competence appraisals, and vice versa. In this vein, humility, associated with low superiority and competitiveness, should elicit lower competence appraisals than pride. The results, however, countered the hypotheses and showed equally high competence perceptions across the three conditions. These results emerged from the two competence scales as well as from the behavioral measure, which assessed the amount of money participants bet on their former opponent winning again. Additional non-parametric tests conducted on the behavioral variable mirrored the picture of the other analyses: The type of reaction did not influence the appraisal of competence differently to any significant extent. Nonetheless, the descriptive data showed that participants invested more and more frequently into the proudly reacting opponent rather than the one who reacted humbly.

The statistically equal effects oppose the expectation that pride conveys more competence than humility. It seems either that a different source of information overrode the expressions or that humility and pride convey messages of competence similarly. There are indications for both explanations. Firstly, in the eye of the participants, all opponents were 
winners; they had already proven themselves as being successful. Participants acknowledged these achievements because, besides being equal, all three conditions yielded very high competence values. What is more, participants ascribed high authentic pride to all of their opponents, independently of condition. This hints to the fact that the mere success was more diagnostic for the perception of competence than the effect of the reaction. Secondly, diverging evidence exists about humility and its relation to both pride and competence. A recent study showed that higher perceived humility led to better social bonds and also higher social status in a group setting (Davis et al., 2013). In the quoted study, the link of humility to competence occurred on the social domain. But the relation of humility might not be limited to this kind of social competence but also affect perceptions of professional competence. Furthermore, some researchers locate humility not separate from pride, but argue that the two emerge together (Richards, 1988; Weidman et al., 2016). This relation of appreciative humility and authentic pride also appeared in the study. Additionally, Weidman et al. (2016) propose an association of appreciative humility with high self-esteem and prestige, which is a means to acquire status by respect and prosociality (Cheng, Tracy, Foulsham, Kingstone, \& Henrich, 2013). This again feeds into the assumption of appreciative humility being associated with prosociality and higher social competence, thereby also with status and professional competence.

However, complementing the main results, two effects at least subtly supported the competence hypotheses. Firstly, although appreciative humility and authentic pride both correlated positively with competence, authentic pride showed the strongest relations. In turn, increasing humility perceptions led to a stronger growth in warmth and liking than increasing authentic pride. Hubristic pride perceptions also correlated strongly with warmth/liking—but in a negative way. This replicates recent studies that link hubristic pride and less liking (Lange \& Crusius, 2015). Concerning the hypotheses, the correlations propose the following: As much as hubristic pride decreases warmth/liking, humility increases it, even more so than 
authentic pride. Authentic pride, in turn, demonstrates an extraordinarily strong relation to competence, which is stronger than the influence of humility.

The second hint to the competence hypotheses stemmed from the ANCOVAs: When the effect of warmth on competence was statistically controlled, the expected pattern emerged for SCM competence: Humble expressions elicited the lowest competence, proud expressions led to the highest competence. Although general competence did not show this effect, the money variable displayed the expected pattern when controlled for warmth (and, at least descriptively, for liking). One careful interpretation would be that someone feeling the exact same warmth for two others would perceive the person reacting proudly as being slightly more competent than the one reacting humbly. However, it is noteworthy that warmth/liking and competence are so highly dependent on one another that eliminating one only leaves a residuum of the other. Nevertheless, slight feelings might tip the scale when managers hire someone, so small effects can decide about a career.

The variable invested money constituted an applied measure of competence in this study. It was not an evaluation along an abstract scale, but a measurement of actual behavior, which might explain why its effects are subtle. Nevertheless, its correlation with SCM competence and the analogical pattern across the three conditions support the assumption of invested money depicting competence in an alternative way. As it implicated direct consequences for the participants, it offers alternative interpretations besides the classical scales, which assessed competence in a merely attitudinal way. In the end, it is a question of application: The warmth/liking scales might be more diagnostic for deliberate evaluations of other people's competence, whereas the behavioral measure applies for decisions to invest resources into others, which is a rather indirect, possibly unconscious competence evaluation.

Countering the expectations of ambivalent stereotyping, the effects of warmth/liking and competence showed high correlations. Ambivalent stereotyping would imply that warmth 
and competence work in opposite directions (Fiske et al., 2002; Judd, James-Hawkins, Yzerbyt, \& Kashima, 2005). Judd et al. (2005), however, discovered a condition that could also apply for the current study: Competence as within-factor led to a negative correlation with warmth, whereas presenting competence between conditions resulted in a positive correlation. The current study had a between-subject design and participants evaluated only one subject, namely their opponent, and did not compare him or her to anybody else. This restriction to the rating of a single target elicited positive correlations of warmth and competence. The effect of one positive dimension spilling over to another dimension as being perceived equally positive is called halo-effect (Asch, 1946; Nisbett \& Wilson, 1977). This effect could provide an explanation for the positive and strong correlations of competence and warmth/liking in the current study: When liking someone, he or she is also ascribed other positive traits, like competence, or the other way round. The halo-effect offers another explanation why increased warmth/liking in the case of humility not only promotes social but also professional competence.

The results of the study demonstrated that humility has a clear benefit over pride when it comes to appraisals of warmth/liking. At first glance, competence is not perceived differently across conditions, benefitting both proudly and humbly reacting people. The manipulation and the set-up of the study serve as possible explanations. The halo-effect as well as associations of humility and social competence suggest processes that increase competence perceptions after humble behavior. Nevertheless, the mere descriptive data, subtly stronger correlations, and the effect of excluding warmth hint to the fact that humble behavior promotes competence evaluations to a less extent than a proud expression. Despite this effect being a lot weaker than the effects on warmth/liking, it still has to be considered when talking about the perception of humility. Furthermore, the following limitations might have also influenced the results and should be discussed before placing the results in a broader context. 


\section{Limitations}

The status of self-abasing humility has already been touched upon. Whereas appreciative humility correlated with general humility, assessed by the approval of the sentence "jul_b reacted humbly to the victory", self-abasing humility did not. Two explanations are possible: Firstly, all statements originate from alleged winners. In the following, self-abasing humility did not—and was not expected to-play an influential role in the study. Secondly, these results replicate the marginal relations between self-abasing humility and humility that Weidman et al. (2016) found. They demonstrate that appreciative humility distinguishes itself in both a higher face-validity and a closer prototypical relation to the overarching construct. Self-abasing humility, however, showed strong positive correlations with hubristic pride and, similar to it, correlated negatively with both warmth/liking and competence. These results propose further research to shed light on the associations and underlying processes of self-abasing humility. A debate on the core of hubristic pride has already begun: Some researchers doubt that the hubristic pride scale truly assesses the second facet of pride, but argue that it measured "over-claiming" of credit (Holbrook, Piazza, \& Fessler, 2014, p. 8). For them, this serves as an explanation as to why hubristic pride is related to low self-esteem, a relation that self-abasing humility shows, too. However, appreciative humility and authentic pride also reveal some remarkable coherence: In the study, they did not only correlate with each other, but both of them were positively related to competence and liking. These effects suggest that the emerging pairs may share some common ground. One relevant factor could be social desirability, because it has repeatedly emerged as a factor differing between the types (Tracy \& Robins, 2007b; Weidman et al., 2016). As it is more than appropriateness or sincerity, it might have played a role in this study, too. Future research should consider adding it as a control variable. The debate about the core of hubristic pride and self-abasing humility as well as authentic pride 
and appreciative humility calls for a closer examination of common underlying roots, processes, and appraisals.

Another problem is the change of four scales' introductory phrase from the pretest to the main study. Initially, the manipulation check scales were retrieved from Tracy and Robins (2007b) and Weidman et al. (2016), who developed them as self-measures starting with "I (generally) feel...". The adaptation of this self-report to an other-report by modifying it to "The other person feels..." made participants of the pretest report discomfort, complaining that they could not judge how someone else felt. To make the study as easy to understand as possible, the sentence was changed to “jul_b is...". There is certainly a difference between evaluating someone else's attributes — how he or she $i s$ - and assuming his or her feelings. Nevertheless, the results of pretest and main study resemble each other, supporting the view that the phrases catch similar constructs. Moreover, it is a researcher's task to make texts and scales as easy to understand and to answer as possible to reduce error variability. Admittedly, when using self-reports to evaluate others, validations and pretests should be obligatory, as some self-reports might not qualify for other-reports. It is important to note that this problem does not occur for the dependent variables. They were assessed by the SCM scales and direct scales, which are intendedly other-reports. However, changing the pride- and humility-scales assimilated them to the SCM scales, which contain "able" (authentic pride scale) and "capable" (SCM competence scale), and "friendly" (SCM warmth scale) and "kind" (appreciative humility scale). One might argue that the assimilation of the introductory phrase increased this overlap. At the same time, the manipulation check variables were not set into relation to the dependent variables in the main analysis. As they later were for exploratory reasons, the respective interpretations should be handled with care. However, the items were developed to depict a certain construct and their similarity might also hint towards the relation of the constructs themselves. 
As explained earlier, it is difficult to define humility, to determine whether it is good or bad, or an emotion, a personality trait, or a sentiment (Ben-Ze'ew, 1993; Davis et al., 2011; Tangney, 2000; Weidman et al., 2016; Weidman \& Tracy, in press). It is possible that, due to this inconsistency, the specific definition of humility in this study does not fully match every participant's understanding. The conducted pretest should prevent such a problem and identify the best statement. But, of course, a pretest only determines the best of the presented statements. As addressed earlier, it could not yet be clarified to what extent the English "humility" corresponds to the German "Bescheidenheit" (let alone to "modesty" and "Demut"). Being a latent construct, "humility" is culturally dependent and consists of different meanings in different societies, which bears difficulties when translating it (Tsuda, 1992; similarly for pride: Neumann, Steinhäuser, \& Roeder, 2009). With that said, "producing" humility is quite challenging, which might be one reason why academics have so rarely investigated the appraisal of experimental humility. The philosopher Richards (1988) addresses this problem:

"How could [humility] express a proper sense of oneself and one's accomplishment to reject something one deserved for it? The objection was that the (deeply humble) hero can't be acting humbly $[\ldots]$ since his behavior cannot express this proper sense of things.” (p. 256)

There is no gesture or facial expression associated with humility, which is a valid method that other emotion research has been using (e.g. with pride: Lange \& Crusius, 2015, or anger: Pietroni, Van Kleef, De Dreu, \& Pagliaro, 2008). Also, Gregg et al. (2008) did not find any clear answer to the question whether humility is perceived hidden or observable. This problem of expression also applies to the differentiation of authentic pride and appreciative humility. Even though they are compared in this study, they have very strong interdependencies and emerge together (Weidman et al., 2016; Weidman \& Tracy, in press). Weidman and his colleagues argue that, as humility is not merely an emotion but also an 
accumulation of feelings, mindsets, and behaviors, it can contain pride. Multiple definitions leave this open, and there is space to investigate on the two constructs' relationship. Nevertheless, the current study demonstrated that a statement could express humility. Although limitations of feasibility, definition, or novelty leave room for improvement, the manipulation check, the reasonable results, and the comparison to both neutral and proud condition show that the effects of humility can be investigated by respective statements.

As a last point, interpretations of the results should be limited to what the study investigated: humility and pride as reactions to success. Therefore, the finding that competence does not differ between the two expressions applies only to situations of preceding success. Nevertheless, to answer the overarching question of the benefits and costs of humility, to address the question of a structural disadvantage for women, or to give advice to young professionals, additional studies are necessary. Whether one should behave humbly or proudly to climb the ladder and win the race also depends on situations in which information about previous success is missing. In line with the finding that people behave humbly towards friends and proudly towards strangers (who do not know about their competence), the factor of information about preceding performance seems to be critical (Tice et al., 1995). In this study, one situation was under investigation, but the effect of pride vs. humility without previously proven competence should also be researched.

\section{Conclusion}

Despite some limitations and challenges that emerged and should be considered for future research, this study showed that humility is a common reaction to success and respectively acknowledged by observers. Producing a humble expression has proven successful and shown significant, meaningful differences to the pride reaction. Although 
competence perceptions did not differ between the proud and humble condition, liking and warmth appraisals were higher after humility than after pride. That is, when shown after success, humility leads to both high liking and high competence evaluations. This finding implies concrete advice for future behavior: If one's successes are well known, reacting humbly is a good option for maintaining and building good relationships and for fostering one's competence standing. When receiving the Nobel Prize, there can be no doubt about one's competence, which is why a truly humble reaction both upholds one's prosocial ascriptions and fosters one's competence. However, when liking is equally high or of less importance, there are indications that it might be safest to behave proudly. As humility could subtly impair competence appraisals, pride is likely the better reaction. However, one has to consider that a proud reaction could hinder liking. Damaging one's warmth/liking perceptions can backfire on competence perceptions as their high correlation suggests. Regarding humility, its negative relations to hubristic pride, its associations with social competence, and the halo-effect indicate the positive effect it might have on competence.

In interactions with co-workers or socially delicate relationships, the decision between humble and proud reactions can have significant consequences. Humility will foster one's social bonds but it could also deter one from persuasively promoting one's successes. For women, who can find themselves in situations where they are expected to comply with their gender role, humility can be the socially desired reaction. But according to the results, it can also put them at a relative disadvantage when their humble demeanor leads others to invest less money into their endeavors.

The idea of humble leadership stems from the conception of authentic leaders, which has evolved during the last decade (May, Chan, Hodges, \& Avolio, 2003; Morris, Brotheridge, \& Urbanski, 2005). But despite collected anecdotes and popular articles (Foster School of Business, 2012; Prime \& Salib, 2014; Walker, 2006), there has been little empirical 
evidence for the effectiveness of this kind of leadership, as Morris et al. confess (2005). What is more, the reported humble leaders were already CEOs. This is well in line with current results: Having proven to be competent, their expressed humility fosters both their competence and social standing. However, research (or anecdotes) on how these humble leaders started their career and how they climbed the ladder, is missing. At the beginning of one's career, a small effect can imply great consequences and authentic pride might lift one higher than humble demeanor.

Eventually, if you want to win the race, several conditions have to be considered: Is the race won primarily by a good relationship or by professional competence? Which kind of relationship to the others do you have or aspire? And do they already know that you are a winner? In the end, authentic pride and appreciative humility are strongly connected and both enhance liking and competence. More importantly, make sure observers neither perceive you as self-abasingly humble nor as hubristically proud. Both would deeply impair liking and competence. To climb the ladder, to stand one's ground in a man's world, or to win the race, both humility and pride have their benefits. Humility has a substantial social advantage, and despite evidence suggesting the benefit of pride when it comes to competence, interpersonal warmth and competence are strongly dependent on each other. Limiting humility to a graceful, social expression would be as restricting as praising it as the most essential trait of leaders. Most importantly, humility and pride are not as dissimilar as some might think. Being aware of their benefits and costs helps combine them to aspire to both liking and competence equally. 


\section{References}

Ambady, N., \& Rosenthal, R. (1992). Thin slices of expressive behavior as predictors of interpersonal consequences: A meta-analysis. Psychological Bulletin, 111, 256-274. http://doi.org/10.1037/0033-2909.111.2.256

Anders, G. (2014, October 21). Google's people chief, Lazlo Bock, explains how to hire right. Forbes. Retrieved December 3, 2016, from http://www.forbes.com/sites/georgeanders/2014/10/21/googles-people-chief-laszlo-bockexplains-how-to-hire-right/\#7d69b41d1a5c

Anderson, C., Hildreth, J. A. D., \& Howland, L. (2015). Is the desire for status a fundamental human motive? A review of the empirical literature. Psychological Bulletin, 141, 574601. https://doi.org/10.1037/a0038781

Asch, S. E. (1946). Forming impressions of personality. The Journal of Abnormal and Social Psychology, 41, 258-290. http://doi.org/10.1037/h0055756

Ashton, M. C., Lee, K., Perugini, M., Szarota, P., de Vries, R. E., Di Blas, L., ... De Raad, B. (2004). A six-factor structure of personality-descriptive adjectives: Solutions from psycholexical studies in seven languages. Journal of Personality and Social Psychology, 86, 356-366. https://doi.org/10.1037/0022-3514.86.2.356

Ben-Ze'ew, A. (1993). The virtue of modesty. American Philosophical Quarterly, 30, 235246.

Caprariello, P. A., Cuddy, A. J. C., \& Fiske, S. T. (2009). Social structure shapes cultural stereotypes and emotions: A causal test of the stereotype content model. Group Processes and Intergroup Relations, 12, 147-155. https://doi.org/doi:10.1177/1368430208101053 
Chancellor, J., \& Lyubomirsky, S. (2013). Humble beginnings: Current trends, state perspectives, and hallmarks of humility. Social and Personality Psychology Compass, 7, 819-833. https://doi.org/DOI 10.1007/s10681-008-9863-6

Cheng, J. T., Tracy, J. L., Foulsham, T., Kingstone, A., \& Henrich, J. (2013). Two ways to the top: Evidence that dominance and prestige are distinct yet viable avenues to social rank and influence. Journal of Personality and Social Psychology, 104, 103-125. https://doi.org/10.1037/a0030398

Cheng, J. T., Tracy, J. L., \& Henrich, J. (2010). Pride, personality, and the evolutionary foundations of human social status. Evolution and Human Behavior, 31, 334-347. https://doi.org/10.1016/j.evolhumbehav.2010.02.004

Cuddy, A. J. C., Fiske, S. T., \& Glick, P. (2008). Warmth and competence as universal dimensions of social perception: The stereotype content model and the BIAS map. Advances in Experimental Social Psychology, 40, 61-149. https://doi.org/10.1016/S0065-2601(07)00002-0

Daubman, K. A., Heatherington, L., \& Ahn, A. (1992). Gender and the self-presentation of academic achievement. Sex Roles, 27, 187-204. https://doi.org/10.1007/bf00290017

Davis, D. E., Hook, J. N., Worthington, E. L., Van Tongeren, D. R., Gartner, A. L., Jennings, D. J., \& Emmons, R. A. (2011). Relational humility: Conceptualizing and measuring humility as a personality judgment. Journal of Personality Assessment, 93, 225-234. https://doi.org/10.1080/00223891.2011.558871

Davis, D. E., McElroy, S. E., Rice, K. G., Choe, E., Westbrook, C., Hook, J. N., ... Worthington, E. L. (2016). Is modesty a subdomain of humility? The Journal of Positive Psychology, 11, 439-446. https://doi.org/10.1080/17439760.2015.1117130 
Davis, D. E., Worthington, E. L., Hook, J. N., Emmons, R. A., Hill, P. C., Bollinger, R. A., \& Van Tongeren, D. R. (2013). Humility and the development and repair of social bonds: Two longitudinal studies. Self and Identity, 12, 58-77. http://doi.org/10.1080/15298868.2011.636509

Eagly, A. H., \& Carli, L. L. (2007). Women and the labyrinth of leadership. Harvard Business Review, 9, 63-71. https://doi.org/10.1111/0022-4537.00234

Exline, J. J., \& Geyer, A. L. (2004). Perceptions of humility: A preliminary study. Self and Identity, 3, 95-114. http://doi.org/10.1080/13576500342000077

Exline, J. J., \& Hill, P. C. (2012). Humility: A consistent and robust predictor of generosity. The Journal of Positive Psychology, 7, 208-218. http://doi.org/10.1080/17439760.2012.671348

Field, A. (2009). Discovering statistics using SPSS (3rd ed.). London: Sage Publications.

Fiske, S. T., Cuddy, A. J. C., Glick, P., \& Xu, J. (2002). A model of (often mixed) stereotype content: Competence and warmth respectively follow from perceived status and competition. Journal of Personality and Social Psychology, 82, 878-902. https://doi.org/10.1037/0022-3514.82.6.878

Flüeler, C. (2009). Einleitung. In C. Flüeler \& M. Rohde (Eds.), Laster im Mittelalter/Vices in the Middle Ages (pp. 7-10). Berlin: Walter de Gruyter GmbH \& Co. KG.

Foster School of Business (2012, September 19). Humility is a key to high performance and effective leadership [Blog post]. Retrieved December 3, 2016, from http://foster.uw.edu/research-brief/humility-is-a-key-to-high-performance-and-effectiveleadership/

Gregg, A. P., Hart, C. M., Sedikides, C., \& Kumashiro, M. (2008). Everyday conceptions of 
modesty: A prototype analysis. Personality and Social Psychology Bulletin, 34, 978992. https://doi.org/https://doi.org/10.1177/0146167208316734

Heilmann, M. E. (2001). Description and prescription: How gender stereotypes prevent women's ascent up the organizational ladder. Journal of Social Issues, 57, 657-674. https://doi.org/10.1111/0022-4537.00234

Herrald, M. M., \& Tomaka, J. (2002). Patterns of emotion-specific appraisal, coping, and cardiovascular reactivity during an ongoing emotional episode. Journal of Personality and Social Psychology, 83, 434-450. https://doi.org/10.1037/0022-3514.83.2.434

Hilbig, B. E., Zettler, I., \& Heydasch, T. (2012). Personality, punishment and public goods: Strategic shifts towards cooperation as a matter of dispositional honesty-humility. European Journal of Personality, 26, 245-254. http://doi.org/10.1002/per.830

Holbrook, C., Piazza, J., \& Fessler, D. M. T. (2014). Conceptual and empirical challenges to the "authentic" versus "hubristic" model of pride. Emotion, 14, 17-32. https://doi.org/10.1037/a0031711

Horberg, E. J., Kraus, M. W., \& Keltner, D. (2013). Pride displays communicate self-interest and support for meritocracy. Journal of Personality and Social Psychology, 105, 24-37. https://doi.org/10.1037/a0032849

Judd, C. M., James-Hawkins, L., Yzerbyt, V., \& Kashima, Y. (2005). Fundamental dimensions of social judgment: Understanding the relations between judgments of competence and warmth. Journal of Personality and Social Psychology, 89, 899-913. http://doi.org/10.1037/0022-3514.89.6.899

Kalokerinos, E. K., Greenaway, K. H., Pedder, D. J., \& Margetts, E. A. (2014). Don’t grin when you win: The social costs of positive emotion expression in performance situations. 
Emotion, 14, 180-186. https://doi.org/10.1037/a0034442

Kesebir, P. (2014). A quiet ego quiets death anxiety: Humility as an existential anxiety buffer. Journal of Personality and Social Psychology, 106, 610-623. https://doi.org/10.1037/a0035814

Klein, E. (1971). A comprehensive etymological dictionary of the English language: Dealing with the origin of words and their sense development thus illustrating the history of civilization and culture. Amsterdam: Elsevier Pub. Co.

Koenig, A. M., Eagly, A. H., Mitchell, A. A., \& Ristikari, T. (2011). Are leader stereotypes masculine? A meta-analysis of three research paradigms. Psychological Bulletin, 137, 616-642. https://doi.org/10.1037/a0023557

Krause, N., Pargament, K. I., Hill, P. C., \& Ironson, G. (2016). Humility, stressful life events, and psychological well-being: Findings from the landmark spirituality and health survey. The Journal of Positive Psychology, 11, 499-510. https://doi.org/10.1080/17439760.2015.1127991

LaBouff, J. P., Rowatt, W. C., Johnson, M. K., Tsang, J.-A., \& Willerton, G. M. (2012). Humble persons are more helpful than less humble persons: Evidence from three studies. The Journal of Positive Psychology, 7, 16-29. https://doi.org/10.1080/17439760.2011.626787

Lange, J., \& Crusius, J. (2015). The tango of two deadly sins: The social-functional relation of envy and pride. Journal of Personality and Social Psychology, 109, 453-472. https://doi.org/10.1037/pspi0000026

Lazarus, R. S. (1991). Emotion and adaptation. New York: Oxford University Press.

Mascolo, M. F., \& Fischer, K. W. (1995). Developmental transformations in appraisals for 
pride, shame, and guilt. In K. W. Fischer \& J. P. Tangney (Eds.), Self-conscious emotions: The psychology of shame, guilt, embarrassment, and pride (pp. 64-113). New York: Guilford Press.

May, D. R., Chan, A. Y. L., Hodges, T. D., \& Avolio, B. J. (2003). Developing the moral component of authentic leadership. Organizational Dynamics, 32, 247-260. https://doi.org/10.1016/S0090-2616(03)00032-9

Miller, G. A., \& Chapman, J. P. (2001). Misunderstanding analysis of covariance. Journal of Abnormal Psychology, 110, 40-48. https://doi.org/10.1037/0021-843X.110.1.40

Morris, J. A., Brotheridge, C. M., \& Urbanski, J. C. (2005). Bringing humility to leadership: Antecedents and consequences of leader humility. Human Relations, 58, 1323-1350. https://doi.org/10.1177/0018726705059929

Neumann, R., Steinhäuser, N., \& Roeder, U. R. (2009). How self-construal shapes emotion: Cultural differences in the feeling of pride. Social Cognition, 27, 327-337. https://doi.org/10.1521/soco.2009.27.2.327

Nisbett, R. E., \& Wilson, T. D. (1977). The halo effect: Evidence for unconscious alteration of judgments. Journal of Personality and Social Psychology, 35, 250-256. https://doi.org/10.1037/0022-3514.35.4.250

Peters, A. S., Rowatt, W. C., \& Johnson, M. K. (2011). Associations between dispositional humility and social relationship quality. Psychology, 2, 155-161. https://doi.org/10.4236/psych.2011.23025

Pietroni, D., Van Kleef, G. A., De Dreu, C. K. W., \& Pagliaro, S. (2008). Emotions as strategic information: Effects of other's emotional expressions on fixed-pie perception, demands, and integrative behavior in negotiation. Journal of Experimental Social 
Psychology, 44, 1444-1454. https://doi.org/10.1016/j.jesp.2008.06.007

Powers, T. A., \& Zuroff, D. C. (1988). Interpersonal consequences of overt self-criticism: A comparison with neutral and self-enhancing presentations of self. Journal of Personality and Social Psychology, 54, 1054-1062. https://doi.org/10.1037/0022-3514.54.6.1054

Prime, J., \& Salib, E. (2014, May 12). The best leaders are humble leaders. Harvard Business Review. Retrieved December 3, 2016, from https://hbr.org/2014/05/the-best-leaders-arehumble-leaders

Richards, N. (1988). Is humility a virtue? American Philosophical Quarterly, 25, 253-259.

Rudman, L. A. (1998). Self-promotion as a risk factor for women: The costs and benefits of counterstereotypical impression management. Journal of Personality and Social Psychology, 74, 629-645. https://doi.org/10.1037/0022-3514.74.3.629

Schlenker, B. R., \& Leary, M. R. (1982). Audiences' reactions to self-enhancing, selfdenigrating, and accurate self-presentations. Journal of Experimental Social Psychology, 18, 89-104. https://doi.org/10.1016/0022-1031(82)90083-X

Shiota, M. N., Keltner, D., \& John, O. P. (2006). Positive emotion dispositions differentially associated with Big Five personality and attachment style. The Journal of Positive Psychology, 1, 61-71. https://doi.org/10.1080/17439760500510833

Singh, V., Kumra, S., \& Vinnicombe, S. (2002). Gender and impression management: Playing the promotion game. Journal of Business Ethics, 37, 77-89. https://doi.org/10.1023/a:1014782118902

Smith, C. A., \& Lazarus, R. S. (1990). Emotion and adaption. In L. A. Pervin (Ed.), Handbook of personality: Theory and research (pp. 609-637). New York: Guilford.

Tangney, J. P. (2000). Humility: Theoretical perspectives, empirical findings and directions 
for future research. Journal of Social and Clinical Psychology, 19, 70-82. https://doi.org/10.1521/jscp.2000.19.1.70

Tice, D. M., Butler, J. L., Muraven, M. B., \& Stillwell, A. M. (1995). When modesty prevails: Differential favorability of self-presentation to friends and strangers. Journal of Personality and Social Psychology, 69(6), 1120-1138. https://doi.org/10.1037/00223514.69.6.1120

Tiedens, L. Z., Ellsworth, P. C., \& Mesquita, B. (2000). Sentimental stereotypes: Emotional expectations for high-and low-status group members. Personality and Social Psychology Bulletin, 26, 560-575. https://doi.org/10.1177/0146167200267004

Tracy, J. L., \& Robins, R. W. (2007a). Emerging insights into the nature and function of pride. Current Directions in Psychological Science, 16, 147-150. https://doi.org/10.1111/j.1467-8721.2007.00493.x

Tracy, J. L., \& Robins, R. W. (2007b). The psychological structure of pride: A tale of two facets. Journal of Personality and Social Psychology, 92, 506-525. https://doi.org/10.1037/0022-3514.92.3.506

Tsuda, S. (1992). Contrasting attitudes in compliments: Humility in Japanese and hyperbole in English. Intercultural Communication Studies, 2, 137-146.

Walker, G. (2006). Review: Good to great: Why some companies make the leap_-and others don't by Jim Collins. Academiy of Management Perspectives, 20, 120-122.

Weidman, A. C., Cheng, J. T., \& Tracy, J. L. (2016). The psychological structure of humility. Journal of Personality and Social Psychology. Advance online publication. http://doi.org/10.1037/pspp0000112

Weidman, A. C., \& Tracy, J. L. (in press). Is humility a sentiment? Behavioral and Brain 
Sciences.

Wosinska, W., Dabul, A. J., Whetstone-Dion, R., \& Cialdini, R. B. (1996). Self-presentational responses to success in the organization: The costs and benefits of modesty. Basic and Applied Social Psychology, 18, 229-242. http://doi.org/10.1207/s15324834basp1802_8 
Appendix

\section{Online access}

Preregistration is available on aspredicted.org:

www.aspredicted.org/blind.php/?x=if69i9

All data, scripts, and screenshots are available on OSF:

https://osf.io/dvt53/?view_only=9f2a56b7e2d943ae9e3ddae1d4482ecb 


\title{
Preregistration
}

\section{CONFIDENTIAL - FOR PEER-REVIEW ONLY}

\section{Aspripedicted}

The Appraisal of Reactions to Success: The Benefits and Costs of Humility (\#2335)

Created: 12/09/2016 02:58 AM (PT)

Shared: 05/09/2017 08:18 AM (PT)

This pre-registration is not yet public. This anomymized copy (without author names) was created by the author(s) to use during peer-review. A non-anomymized version (containing author names) will become publicly avallable elther when an author makes it public, or three years from the "Shared" date at the top of this document (whichever comes first). Until that time the contents of this pre-reglatration are confidential.

\author{
1) What's the main question beling asked or hypothesis being tested in thls study? \\ The evaluation of other people depending on their reaction to success: \\ Percelved warmth/liking is lowest in the pride condition and higher in the humble than in the neutral condition. Percelved competence is highest in \\ the pride condition and lower in the humble than in the neutral condition.
}

2) Describe the key dependent varlable(s) specilying how they will be measured.

Competence 1: Amount of money invested for betting on another success of the former opponent

Competence 2: items measuring competence derlved from the stereotype content model (Eagly et al, 2002)

Competence 3: items developed to measure percelved competence ( $X X$ is good in such word games. $X X$ is competent. $X X$ has high verbal abilitles.)

Uling 1: Items measuring warmth derlved from the stereotype content model (Eagly et al., 2002)

Uling 2: Items used to measure liking in pride-research (Cruslus \& Lange, 2015)

\section{3) How many and which conditions will particlpants be assigned to?}

Three conditions: All particlpants bose in the bogus competition. In the following, they are assigned to one of three reactions by their opponent:

1. Pride reaction (cool that I won. I am proud of myself. let's see what's coming up next)

2. Humble reaction (cool that I won. I'm sure it was clase. let's see what's coming up next)

3. Neutral reaction (let's see what's coming up next)

\section{4) Specify exactly which analyses you will conduct to examine the main question/hypothesis.}

Items are agregated and mean values for each one of the five dependent varlables (DVs) are generated. ANONAs for the five DVs show significant main effects (significance level of 5\%) between the three conditions. Planned contrasts show the following significant differences:

More money is invested in the pride than in the neutral condition. Further, less is imested in the humble than in the neutral condition. Uliewise, competence ratings are significantly higher in the pride than in the neutral condition and lower in the humble compared to the neutral condition. uling/Warmth ratings are slgniflcantly lower in the pride condition than in the neutral condition but higher in the humble than in the neutral condition.

\section{5) Any secondary analyses?}

Correlational analysis to determine construct validity of competence: whether the three operationalizations/measurements of competence are all measuring the same construct. Ukewise, If the two scales of liking/warmth are both measuring the same construct.

\begin{abstract}
Manipulation checks: Proud condition will be percelved as prouder than the neutral and humble condition. Equally, the humble condition will be percelved as more humble than the pride and neutral condition. However, the conditions do not differ in adequacy of the reaction. Further, proud opponents are percelved as higher in authentic and hubristic pride but lower on self-abasing and appreclative humility than opponents from the neutral condition. In contrast, humble opponents are perceived as higher in both types of humilty (especlally in appreclative humility) than opponents from the neutral and pride condition. Further, they are evaluated lower in hubristic pride than particlpants of the pride condition.
\end{abstract}

6) How many observations will be collected or what will determine sample she? No need to justify decision, but be preclee about exactly how the number will be determined.

We will test 200 participants or until mid-January, whichever comes first.

7) Anything else you would like to preregister? (e.-. data exclusions, varlables collected for exploratory purposes, unusual analyses planned?) Data exclusion: Participants are excluded on the following criterla:

- If they don't believe that the competition is real

-If they don't believe that they really lost the competition

-If they don't believe in the existence of the competitor

Exploratory data: percelved sincerity of the reaction and deservingness of the victory are conducted for exploratory analysis.

8) Have any data been collected for this study already?

No, no data have been collected for this study yet 


\section{Pretest}

\section{Statements}

Pr 1: Gewonnen! Bin stolz auf mich. (I won! I am proud of myself.)*

Pr 2: Gewonnen! Hab ich gut gemacht.

Pr 3: Gewonnen! Manchmal läufts einfach gut.

Hu 1: Gewonnen! War aber bestimmt knapp. (I won! But it was certainly close.)*

Hu 2: Gewonnen! Jetzt wär ne Gelegenheit zur Revanche cool.

Hu 3: Gewonnen! Du warst aber sicher auch gut.

$$
\text { * statements chosen for the main study }
$$

Mean values of statements on variables of interest

\begin{tabular}{lccccccccccc} 
& Direct H & Direct P & Se & Apr & Ac & Si & AP & HP & AH & SH \\
\hline Pr1 & 1.74 & 4.42 & 4.42 & 3.21 & 2.95 & 3.58 & 3.93 & 3.09 & 1.73 & 1.35 \\
Pr2 & 1.47 & 4.47 & 4.58 & 2.84 & 2.89 & 3.32 & 4.04 & 3.28 & 1.78 & 1.52 \\
Pr3 & 3.26 & 2.74 & 2.47 & 3.47 & 3.63 & 3.79 & 2.87 & 1.93 & 2.94 & 2.2 \\
Hu1 & 3.95 & 2.68 & 2.26 & 3.58 & 3.21 & 3.52 & 3.22 & 1.84 & 3.68 & 2.08 \\
Hu2 & 2.79 & 2.95 & 2.32 & 3.52 & 3.32 & 3.47 & 3.78 & 2.14 & 3.18 & 1.68 \\
Hu3 & 3.53 & 2.89 & 2.21 & 3.21 & 3.32 & 2.79 & 3.36 & 2.12 & 3.66 & 2.21
\end{tabular}

Note. H: Humility, P: Pride, Sc:Self-centeredness, Apr: Appropriateness, Ac: Accurate self-view, Si: Sincerity, AP: Authentic pride, HP: Hubristic pride, AH: Appreciative humility, SH: Self-abasing humility

Results of t-tests assessing the differences between variables for each statement

\begin{tabular}{lccrrrrrrrrr} 
& \multicolumn{1}{c}{ Direct H vs. Direct P } & \multicolumn{2}{c}{ AP vs. AH } & \multicolumn{2}{c}{ HS vs. AH } & \multicolumn{2}{c}{ AP vs. SH } & \multicolumn{2}{c}{ HP vs. SH } \\
\cline { 2 - 11 } & \multicolumn{1}{c}{$t(18)$} & \multicolumn{1}{c}{$p$} & \multicolumn{1}{c}{$t(18)$} & \multicolumn{1}{c}{$p$} & \multicolumn{1}{c}{$t(18)$} & \multicolumn{1}{c}{$p$} & \multicolumn{1}{c}{$t(18)$} & \multicolumn{1}{c}{$p$} & \multicolumn{1}{c}{$t(18)$} & $p$ \\
\cline { 2 - 11 } Pr1 & -13.22 & $<0.001$ & 11.66 & $<0.001$ & 6.28 & $<0.001$ & 14.05 & $<0.001$ & 7.80 & $<0.001$ \\
Pr2 & -10.88 & $<0.001$ & 9.22 & $<0.001$ & 6.07 & $<0.001$ & 6.70 & $<0.001$ & 7.41 & $<0.001$ \\
Pr3 & 1.11 & 0.281 & -0.30 & 0.768 & -3.14 & 0.006 & 2.38 & 0.029 & -0.81 & 0.427 \\
Hu1 & 3.18 & 0.005 & -1.92 & 0.071 & -4.81 & $<0.001$ & 5.12 & $<0.001$ & -0.82 & 0.425 \\
Hu2 & -0.51 & 0.615 & 3.05 & 0.007 & -3.75 & 0.001 & 9.45 & $<0.001$ & 2.60 & 0.018 \\
Hu3 & 1.61 & 0.124 & -1.20 & 0.246 & -3.62 & 0.002 & 5.43 & $<0.001$ & -0.28 & 0.780
\end{tabular}

Note. H: Humility, P: Pride, AP: Authentic pride, HP: Hubristic pride, AH: Appreciative humility, SH: Selfabasing humility 


\section{Universität zu Köln}

Humanwissenschaftliche

Fakultät

Department Psychologie

Prüfungsamt

Gronewaldstraße 2a

50931 Köln

\section{Erklärung zu verwendeten Hilfsmitteln}

Name, Vorname

Matrikel-Nr.:

Hiermit versichere ich, dass ich diese

$\square$ Hausarbeit,

$\square$ Bachelorarbeit,

$\square$ Masterarbeit,

$\square$ Diplomarbeit,

selbstständig verfasst und keine anderen als die angegebenen Quellen und Hilfsmittel benutzt habe. Die Stellen meiner Arbeit, die dem Wortlaut oder dem Sinn nach anderen Werken und Quellen, einschließlich der Quellen aus dem Internet, entnommen sind, habe ich in jedem Fall unter Angabe der Quelle als Entlehnung kenntlich gemacht. Dasselbe gilt sinngemäß für Tabellen, Karten und Abbildungen. 